NBER WORKING PAPER SERIES

\title{
THE LONG-RUN IMPACTS OF EARLY CHILDHOOD EDUCATION: EVIDENCE FROM A FAILED POLICY EXPERIMENT
}

\author{
Philip DeCicca \\ Justin D. Smith \\ Working Paper 17085 \\ http://www.nber.org/papers/w17085
NATIONAL BUREAU OF ECONOMIC RESEARCH
1050 Massachusetts Avenue
Cambridge, MA 02138

May 2011

We thank Oscar Bedard, Elizabeth Dhuey, Steve Pischke, Fabian Waldinger, and seminar participants at the University of Manitoba, the University of Winnipeg, and the Society of Labour Economists for valuable comments. All errors are our own. The views expressed herein are those of the authors and do not necessarily reflect the views of the National Bureau of Economic Research.

NBER working papers are circulated for discussion and comment purposes. They have not been peerreviewed or been subject to the review by the NBER Board of Directors that accompanies official NBER publications.

(C) 2011 by Philip DeCicca and Justin D. Smith. All rights reserved. Short sections of text, not to exceed two paragraphs, may be quoted without explicit permission provided that full credit, including @ notice, is given to the source. 
The Long-Run Impacts of Early Childhood Education: Evidence From a Failed Policy Experiment Philip DeCicca and Justin D. Smith

NBER Working Paper No. 17085

May 2011

JEL No. I21,I28,J24

\title{
ABSTRACT
}

We investigate short and long-term effects of early childhood education using variation created by a unique policy experiment in British Columbia, Canada. Our findings imply starting Kindergarten one year late substantially reduces the probability of repeating the third grade, and meaningfully increases in tenth grade math and reading scores. Effects are highest for low income students and males. Estimates suggest that entering kindergarten early may have a detrimental effect on future outcomes.

\author{
Philip DeCicca \\ Department of Economics \\ 422 Kenneth Taylor Hall \\ McMaster University \\ Hamilton, ON L8S 4M4 \\ CANADA \\ and NBER \\ decicca@mcmaster.ca \\ Justin D. Smith \\ Department of Economics \\ 648 Fletcher Argue Building \\ University of Manitoba \\ Winnipeg, MB R3T 5V5 \\ CANADA \\ smith44@cc.umanitoba.ca
}




\title{
The Long-Run Impacts of Early Childhood Education: Evidence from a Failed Policy Experiment*
}

\author{
Philip DeCicca \\ Department of Economics \\ McMaster University \\ Justin Smith \\ Department of Economics \\ University of Manitoba
}

May 2011

\begin{abstract}
We investigate short and long-term effects of early childhood education using variation created by a unique policy experiment in British Columbia, Canada. Our findings imply starting Kindergarten one year late substantially reduces the probability of repeating the third grade, and meaningfully increases in tenth grade math and reading scores. Effects are highest for low income students and males. Estimates suggest that entering kindergarten early may have a detrimental effect on future outcomes.
\end{abstract}

\section{Introduction}

Early childhood programs are an important part of intellectual development, as they allow children to build a solid learning base, accumulate human capital at a higher rate in the future, and therefore perform better in school and in the labor market. The benefits may be especially important for disadvantaged children, since the early skill gap between them and their more advantaged peers can appear early and persist through time [Cunha et al., 2006]. Using early childhood programs to close early skill gaps will help to prevent future skill gaps from forming. There are many empirical analyses of small scale early interventions like the Perry Pre-School experiment, and larger ones like

${ }^{*}$ We thank Oscar Bedard, Elizabeth Dhuey, Steve Pischke, Fabian Waldinger, two anonymous referees, seminar participants at the University of Manitoba, the University of Winnipeg, and the Society of Labour Economists (SOLE) for valuable comments. All errors are our own. 
Head Start, that support these ideas by showing positive impacts on a variety of short and long term outcomes. On the other hand, fewer researchers have examined the effect of universal programs like Kindergarten or pre-Kindergarten (pre-k). Kindergarten is arguably the most widespread early childhood education program, and is continuing to expand. For example, in the U.S. the availability of Kindergarten expanded rapidly across the country in the 1960s and 1970s. More recently, several states have launched universal pre-k programs. In Canada, Ontario and British Columbia (BC) moved from half day to full day Kindergarten in 2010, while similar expansions are being considered in other provinces.

This paper examines the effects of a unique natural experiment in BC that altered students' early education experience. In the 1990-1991 school year, BC mandated a program called "dual entry," where students entered school at two different points in the school year, rather than the traditional single entry system used prior to that date. More specifically, students turning five years old between May and October 1990 were allowed to enter Kindergarten in September 1990, but students born between November 1990 and April 1991 were allowed to start 4 months later in January 1991. The program was abruptly terminated in May, 1991, leaving January entrants in abeyance after completing only 6 months of Kindergarten. To unwind the program, the government provided $\$ 7$ million in financial support for November-December born children to move to first grade at the start of the next school year, but no support was given for January-April students. Consequently, November-December students were kept in Kindergarten for as little as 6 months, and January-April students were kept for as many as 16 months. Based on this variation, we can think of November-December children as having started Kindergarten 4 months late, and January-April students as having started 6 months early.

We estimate the impact of the policy on the probability of grade repetition at age nine and fifteen, and on tenth grade math and reading scores, using a difference in differences estimator. The estimator compares outcomes of treated groups - students born between November and April - to control groups within a policy year to similar differences in a year when the policy did not exist. We find that starting Kindergarten one year late reduces the probability of repeating a grade by up to 3.2 percentage points by age nine, and by up to 4.3 percentage points by age fifteen. We also find that starting Kindergarten one year late improves tenth grade math scores by up to 0.089 
standard deviations, and tenth grade reading scores by up to 0.144 standard deviations. The size of the estimated effects is largest for students in the lowest income quartiles, and for males.

Taken at face value, the estimates imply that spending less time in Kindergarten improves student performance. The variation created by this policy is, however, more complex. While starting school later reduces time spent in Kindergarten, it may also improve school readiness by increasing the age, and therefore physical and emotional maturity, at which students first enter formal schooling. One explanation for our result is that the positive impact of increased maturity outweighs the effect of reductions in Kindergarten, all the way to tenth grade. Another important factor is the counterfactual to spending one extra year in Kindergarten. In the absence of extra Kindergarten some children would stay at home, and others would enroll in day care. If these alternative uses of time provide a benefit to students compared to Kindergarten, this supports the effect we observe. Viewed in this way, our results are consistent with some studies in the child care literature, which show that preschool care can negatively impact on a variety of child outcomes. ${ }^{1}$ Finally it is unknown whether students remaining in Kindergarten for more than 10 months were challenged at a more advanced level by their teacher, and whether students who moved ahead to grade 1 after 6 months in Kindergarten were accommodated in some way. Because such students were mixed together in classrooms with students progressing regularly through school, this reduces the likelihood that teachers were able to make special arrangements.

Keeping issues of interpretation in mind, the results are generated from a fairly specific policy experiment that did not originally intend to alter exposure to Kindergarten. Still, they can be interpreted in at least two useful ways. First, they approximate the potential impact of introducing a pre-k program where one did not previously exist. Introducing such a program would increase time spent in school, which comes at the expense of time spent at home, and would also lower a student's entry age and readiness. For both grade repetition and tenth grade test scores, the estimates imply poorer outcomes for children who participate in such a program. The estimates are also useful as an interesting case study. In unwinding the dual entry policy, the government likely did not fully anticipate the impact their actions would have on students who were held back or moved ahead. The results show a long term effect of the government action on the affected

\footnotetext{
${ }^{1}$ See Baker et al. [2008], Lefebvre et al. [2011], Herbst and Tekin [2010], and Magnuson et al. [2007] for examples.
} 
students.

\section{Existing Literature}

Most of the available evidence on the introduction of Kindergarten or pre-k shows positive effects on student outcomes. In Tulsa, Oklahoma, a comparison of students of a similar age who are just about to start pre-k to students who just finished shows that pre-k finishers had improved test scores by 0.24 to 0.39 standard deviations $(\sigma)$ [Gormley and Gayer, 2005]. The introduction of universal pre-k in Georgia increased student test scores by $0.12 \sigma$, and increased probability of being on-grade for age for students in the program who are disadvantaged or who live in low-density areas of the state [Fitzpatrick, 2008]. On a larger geographic scale, the introduction of Kindergarten programs in the U.S. in the 1960's and 70's lowers the probability that white students aged 5 drop out of high school by 2.5\%, and lowers the probability of being institutionalized by 20\% [Cascio, 2009]. Furthermore, increased Kindergarten enrollment as a result of this expansion is associated with a decline in the probability of failing a grade for male, non-white, disadvantaged students, and a positive effect on attainment and wages for non-white males [Dhuey, Forthcoming].

A related literature shows the effect of moving from full- to half-day kindergarten. The main findings are that students in the full-time program perform better [Walston and West, 2004], but that the effects can dissipate quickly over the subsequent few grades of school, especially for minority students [Cannon et al., 2006; Cooper et al., 2010; DeCicca, 2007].

Counter to the results above, increased child care utilization resulting from the province of Quebec's universal $\$ 5$ per day child care policy results in worse student outcomes [Baker et al., 2008]. More specifically, while the subsidized day care increased utilization by $14 \%$ among $0-4$ year olds, there are associated negative effects on measures of anxiety, physical aggression, hyperactivity, and various health outcomes for children under 4. The effect on test scores as measured by the Peabody Picture Vocabulary Test (PPVT) at age 4 are statistically insignificant. In more recent research, the same policy is shown to negatively affect the PPVT scores of 5 year olds by up to 0.25 standard deviations, with negative effects being larger among children of low-educated mothers

[Lefebvre et al., 2011]. Additional evidence from the United States suggests that preschool care 
can have a negative impact on students' early cognitive achievement [Herbst and Tekin, 2010], and behavioural outcomes [Magnuson et al., 2007].

A related strand of literature looks specifically at more targeted early educational interventions on student outcomes. In a comprehensive literature survey, Currie [2001] shows that there are likely short and medium term benefits to early interventions on a small-scale (such as the Perry Preschool Experiment) and a larger scale (such as Head Start). Research on Head Start is particularly important as it serves a large number of people, and its effects can be compared to a Kindergarten program much more easily than a smaller-scale intervention. Comparing the outcomes of siblings, Currie and Thomas [1995] show that overall Head Start improves student test scores by about 6 percentiles, and reduces the probability of repeating a grade by 47 percent. Interestingly, the Head Start effect declines over time for black students, but not for whites. Looking specifically at Hispanic children, Currie and Thomas [1999] show that Head Start leads to significant benefits in terms of test scores and grade repetition. Using longer-term outcomes, Garces et al. [2002] show that for white students participating in Head Start lowers the probability of dropping out of high school by 20 percentage points, increases the likelihood of attending university by 18 percentage points, and may increase earnings. Finally, Ludwig and Miller [2008] estimates that Head Start lowers mortality rates among 5-9 year olds by up to 50\%, and some evidence of an increase in educational attainment.

\section{Background on Schooling in British Columbia}

With minor exceptions, the public school system in BC is very similar to other jurisdictions across Canada and the United States. Education is a provincial responsibility in Canada, so all legislation and regulation governing the school system are decided at the provincial level. The province is separated into 60 school districts whose boundaries correspond to city boundaries in the populated areas in the southwest, but encompass much larger areas in the less-populated north. A separate, province-wide district exists for French-speaking (Francophone) schools. ${ }^{2}$ The provincial Ministry of Education sets general rules for the operation of schools, such as the curriculum, while the districts

\footnotetext{
${ }^{2}$ Student enrollment in this district accounts for less than $1 \%$ of total enrollment
} 
are responsible for the actual implementation of education.

The Ministry of Education allocates funding directly to districts using a per-student formula, where each "full-time equivalent" is allocated just under $\$ 7,000 .^{3}$ Additional funds are provided for Aboriginal education, English as a Second Language (ESL), Special Education (SpEd), and other factors. The districts in turn decide how to distribute the money to schools, though this process is not transparent. Unlike the American system, school districts do not raise their own funds through property taxes in $\mathrm{BC}$.

About $10 \%$ of students attend private schools. While these schools are relatively free to choose the perspective through which they deliver education, in practice most private schools have a religious focus. What is unique about BC's private schools is that they are partially funded by the government depending on their adherence to the curriculum and other administrative requirements. Schools can receive at most $50 \%$ funding, but may receive $35 \%$ or none at all. Currently, the vast majority receive $50 \%$ funding.

Prior to 2003, students attending public schools were required to attend their neighborhood school. The province has since introduced legislation allowing parents to choose any public school, but this has not really been successful in creating public school choice. The realistic forms of school choice are between public and private education, or between French Immersion and non-French Immersion public schools. What differentiates French Immersion schools from other schools is that the first four years of instruction are conducted mostly in French. In large school districts such as the Vancouver School Board, French Immersion and non-French Immersion schools have their own catchment areas, allowing parents the choice of both in a local area. Elsewhere, a French immersion school could be a fair distance away from a student's home. In practice, it is often difficult to enroll in French Immersion schools due to high demand.

The first compulsory grade in BC is Kindergarten, which children are supposed to start in the calendar year they turn five. Parents are allowed to delay entry into Kindergarten for one year, but in practice only about $3 \%$ of parents exercise this option. For most districts, students attend

\footnotetext{
${ }^{3} \mathrm{~A}$ full-time equivalent stands for a student who attends school full-time. All students in first through seventh grades are equal to one full-time equivalent. Since students in Kindergarten attend for half a day, they are considered half of a full-time equivalent. Students in high school are between half and one full-time equivalent depending on the number of courses taken.
} 
elementary schools until seventh grade, then transfer to a high school until twelfth grade. In a small number of districts, students transfer from an elementary school to a middle school after fifth grade, then to a high school after eighth grade. School is compulsory until age sixteen.

Prior to school year 1999-2000, standardized tests were conducted on different subjects each year for students in fourth, seventh, and tenth grades. Students in twelfth grade wrote Provincial Exams at the end of core courses such as English, Math, and Science if they had enrolled in those classes. In 1999-2000, the province instituted the Foundation Skills Assessment, testing all fourth, seventh, and tenth grade students yearly in reading, writing, and math. Since 2003-2004, tenth grade students are no longer tested as part of the Foundation Skills Assessment, but are instead tested as part of the Provincial Exams along with eleventh and twelfth grade students. The tenth grade Foundation Skills Assessment tests serve as our outcomes of interest.

\section{Empirical Framework}

\subsection{BC's Dual Entry Experiment}

Variation in Kindergarten entry comes from a unique policy implemented in BC in the 1990-1991 school year. Just prior to the start of that school year, the BC Ministry of Education mandated a school entry structure called "dual entry," in which children turning 5 years old between May 1 and October 31, 1990 started school in September 1990, and students born between November 1, 1990 and April 30, 1991 started a few months later in January, 1991. Before that time, students turning five years old in any given calendar year all began school together in September. ${ }^{4}$ For what follows, it is useful to recast the school entry system as a relationship between birth dates and school entry. Under the dual entry structure, students born between May 1 and October 31, 1985 started school in September 1990, and students born between November 1, 1985 and April 30, 1986 started school in January 1991.

Dual entry was repealed in May, 1991 and replaced with the single entry system that existed pre-

\footnotetext{
${ }^{4}$ Dual entry was piloted in the 1989-1990 school year for a select number of districts on a voluntary basis. In theory this would provide us with a nice experiment with which to identify the effect of the dual entry policy. In practice, we unfortunately have no information on which districts allowed dual entrants, nor do we have information on student entry ages for 1989.
} 
viously. As part of the plan to unwind the program, the government offered extra funding for school boards to accommodate November-December born children into grade 1 classrooms in September, 1991, but did not offer funding for January-April born children. ${ }^{5}$ November-December children could therefore move on to grade 1 after completing as little as 6 months of Kindergarten, while January-April were kept in Kindergarten for as many as 16 months total. The policy thus creates variation in student school start age and simultaneously the amount of time spent in Kindergarten. It is useful to think of the November-December students as starting Kindergarten 4 months late relative to a normal single-entry cohort, and the January-April students starting 6 months early relative to a normal single entry cohort. This variation in late and early Kindergarten entry is the policy we evaluate in this study.

Figure 1 illustrates the variation in school entry age by plotting average student entry age against month of birth separately for students born in 1985, 1986, and 1987. The policy raised entry age for November-December students in 1985, and lowered it for January-April students in 1986. The policy was fully unwound in 1987, so that line represents normal entry age under a single entry structure. Because of the way students were sorted into classrooms after the repeal of the policy, compliant November-December students experienced as little as 6 months of Kindergarten, January-April students experienced up to 16 months, and others experienced $10 .{ }^{6}$

The description above and the associated graphs represent the effect of the policy on compliant students. Non-compliance did occur among BC students, mainly because parents have the option to delay entry. Such non-compliance means that student entry age is not fully exogenous. On the other hand, expected entry age, which we define as the entry age for students who comply completely with the rules, is arguably exogenous because it depends only on student birth date. We therefore correct for the effects of delayed entry by using expected entry age as an instrument for observed entry age. One potential threat to the exogeneity of expected entry age is that parents could in theory plan dates of birth by timing conception or choosing specific birth dates through c-sections and induced births. In practice such manipulation would not have been possible because

\footnotetext{
${ }^{5}$ At the time, Kindergarten was half-day, but grade 1 was full-day. Extra funding was necessary to pay for the extra resources needed to teach children for a full day.

${ }^{6}$ Note that the line for 1985-born students is missing the first 4 data points due to a sample exclusion, explained below
} 
this policy was implemented years after all affected students were born.

A related issue is that not all students who comply with the entry date rules follow into Kindergarten or grade 1 in the expected way. In September, 1991, schools allowed some NovemberDecember children to remain in Kindergarten, and allowed some January entrants to move ahead to grade 1. This implies that, for the average student, increases in entry age are not completely offset by reductions in time spent in Kindergarten. While this does not affect the internal validity of our estimator, it does affect the interpretation depending on how many students failed to follow the expected structure. To understand the extent of this issue, Table 2 reports counts of the number of students observed at entry for several subgroups of students. Panel A displays the year and grade of the first observation for each student born in 1985, and separately, 1987. Because data is collected once per year in October since 1990, November-December students who follow the above structure should first be observed in grade 1 in 1991. Out of 7,188 students total, 3,512 are observed in grade 1 in 1991. Of the remaining students, 2,124 are observed in Kindergarten in 1990, four months earlier than expected. The final 1,552 are observed in Kindergarten in 1991, meaning they delayed entry or entered the previous January but stayed in Kindergarten. If all 1,552 entered Kindergarten in January, this implies that 5,064 students began in January, and 3,512 (69\%) stayed in Kindergarten for six months. The true fraction, however, is likely much higher since at least some of the 1,552 students are delayed entrants. Entry year and grade for the 1987 cohort, who are not affected by the policy, is also presented for comparison. In this cohort, roughly $7 \%$ of the students delay entry, and others start on time.

In Panel B we perform the same comparison for January-April births. Students born in 1986 who are first observed in Kindergarten in 1991 are either on time students or delayed entrants. Students observed in grade 1 began Kindergarten in January, and moved ahead to grade 1. While we cannot separate the January-entrants from the delayed entrants among students observed in Kindergarten in 1991, data from the 1987 birth cohort suggests that very few students delay entry. This comparison may not be completely accurate, since the policy may have induced an abovenormal number of parents to delay their child's entry. It is unlikely, however, that a very large number of those students delayed, given the pattern among the November-December entrants (i.e. at most $31 \%$ delayed entry). 
In sum, the evidence from Table 2 suggests that the majority of students who entered Kindergarten in January, 1991 experienced variations in the amount of time in Kindergarten suggested above. $^{7}$ Thus, for the average student, an increase in entry age of one year implies close to a one year reduction in time spent in Kindergarten, so we maintain the interpretation of our variation in entry age as being equal to starting Kindergarten 4 months late for November-December students, and 6 months early for January-April students.

Finally, we note that while the main effect of the policy was to alter Kindergarten entry, there may have been other side-effects. January entrants were not placed into separate classes upon entry; rather they joined their peers who had already been in school for 4 months, and this appears to have been done without increasing the number of classrooms or teachers. ${ }^{8}$ This may have created a difficult problem for teachers that had to teach two groups of students in different parts of the learning process. If age-related peer effects exist, they could be responsible for part of the effect we see. Relatedly, the addition of a group of younger children to an existing classroom would have altered the relative age structure of the classroom. Prior to students entering in January 1991, October-born students who entered in September, 1990 were the youngest in the class. Once November-April born students entered in January 1991, the October-born were in the middle of the age distribution. Furthermore, in single-entry cohorts, April-born students are among the older group at entry, whereas under dual entry they are the youngest. To the extent that relative age matters, this could also impact the estimates. Evidence suggests that relative age, however, is not an important determinant of student outcomes [Cascio and Schanzenbach, 2007].

\footnotetext{
${ }^{7}$ One last possibility is that January-April born students remained in Kindergarten until January, 1992, then moved to grade 1, and to grade 2 in September, 1992. An article from the Vancouver Sun dated January 1992 suggests that this might have been allowed in some jurisdictions. The data, however, do not support that this was widespread in BC. In the data this would look as though a student "skipped" grade 1, since data would not have been collected while the student was in grade 1. While we do not observe an abnormal amount of skipping grade 1, roughly 1,770 January-April students skip grade 3. We treat this as a ballpark estimate of the number of students who stayed in Kindergarten for only 10 months.

${ }^{8}$ Details discussed in McTavish [1990] indicate that the province had no plan initially to increase the number of teachers or classrooms. Had the program proceeded further, this may have been necessary depending on how many students proceeded as scheduled in the dual entry program. Since the program was cancelled, this likely never became an issue. In fact, such logistical problems was one of the major reasons for the cancellation of the program.
} 


\subsection{Measurement Approach}

Using the policy described above, we sort students into treatment and control groups based on their month and year of birth and summarize this allocation in Table 1. Students born in November to December, 1985 are defined as a treated group because they began Kindergarten 4 months late. Students born between January and April, 1986 are another treated group because they began Kindergarten 6 months early. Students born outside those time periods are in the control group because they began Kindergarten at the normal time. We then use a difference in differences approach to identify the effects of the policy on student outcomes. Intuitively, this estimator compares the outcomes of treated and non-treated groups in a policy year, using the difference between the same two groups in a non-policy year as the counterfactual.

The difference in differences estimates are obtained from the following empirical model:

$$
\begin{aligned}
O_{i} & =\beta_{0}+\beta_{1} A E_{i}+\beta_{2} d_{85}+\beta_{3} d_{86}+\beta_{4} d_{J A}+\beta_{5} d_{N D}+\beta_{6} b d_{i}+\mathbf{x}_{\mathbf{i}}^{\prime} \beta_{\mathbf{7}}+\nu_{1 i} \\
A E_{i} & =\alpha_{0}+\alpha_{1} A E_{i}^{e}+\alpha_{2} d_{85}+\alpha_{3} d_{86}+\alpha_{4} d_{J A}+\alpha_{5} d_{N D}+\alpha_{6} b d_{i}+\mathbf{x}_{\mathbf{i}}^{\prime} \alpha_{\mathbf{7}}+\nu_{2 i t}
\end{aligned}
$$

$O_{i}$ is a student outcome; $A E_{i}$ is actual Kindergarten entry age; $A E_{i}^{e}$ is the expected Kindergarten entry age based on school start rules; $d_{85}$ and $d_{86}$ are year of birth dummies; $d_{J A}$ and $d_{N D}$ are dummies indicating whether the student is born in January to April (JA) or November to December $(\mathrm{ND}) ; b d_{i}$ is day of birth within the year; $\mathbf{x}_{\mathbf{i}}$ is a collection of control variables; $\nu_{1 i t}$ and $\nu_{2 i t}$ are error terms.

The coefficient of interest is $\beta_{1}$, which gives the difference in differences estimate, and is interpreted as the effect of entering Kindergarten one year late on the outcome. $A E_{i}$ is akin to the interaction term in regular difference-in-differences regressions (the "policy" variable), but in our case its value adjusts estimates for the treatment intensity and direction: students born in November-December have a higher entry age by roughly 4 months, and January-April students have a lower entry age by 6 months. We instrument $A E_{i}$ with $A E_{i}^{e}$ in a first stage because of the compliance issue discussed in the previous subsection. $f\left(b d_{i}\right)$ controls for any underlying relation-

ship between $O_{i t}, A E_{i}^{e}$ and date of birth. The structural parameters are estimated by Two-Stage Least Squares (2SLS), and we also present the first stage and reduced form estimates. As discussed 
below, we cannot identify precise school start ages for some treated students, so some readers might prefer the reduced form. We interpret $\beta_{1}$ as a Local Average Treatment Effect (LATE) because we expect that there are heterogeneous treatment effects. Our estimates therefore apply to those students whose Kindergarten entry age was manipulated by the policy.

\section{Data}

\subsection{Data and Sample Description}

The primary data are administrative student records from the Ministry of Education in BC. On a yearly basis since 1990, the Ministry collects data on all public and private school students in the BC school system. The data contain information on the school each student attends, their grade level, special education status, English as a second language (ESL) status, a small set of personal characteristics, date of birth, and home postal code (for all records after 1996). ${ }^{9}$ No parent income or education information is available in the data. We proxy for these factors by linking aggregated census data to students via their school's postal code. ${ }^{10}$ Students are tracked over time and across schools through an encrypted student identifier as long as they remain in the BC school system; no information is available for students who leave the system.

Administrative records are linked to test scores on the Foundation Skills Assessment (FSA), BC's mandatory annual standardized test for students in fourth, seventh, and tenth grade. At the end of each school year since 1999, students are tested in the areas of math, reading, and writing. From both the student and teacher perspective, the FSA is low-stakes, as the results do not count towards students' final grades nor do they determine the pay of any individual teacher.

\footnotetext{
${ }^{9}$ The Canadian postal code is a 6-digit code made up of alternating (L)etters and (N)umbers in the following format: LNL NLN. The first three digits are called the Forward Sortation Area, and define a relatively large space. The full 6-digit code, however, can identify an area as small as one side of a neighborhood block in urban areas. The Forward Sortation area is similar to the U.S. Zip code, where as the 6-digit postal code is something like the Zip +4 .

${ }^{10}$ Specifically we include average household income, fraction with a highest level of schooling of university, fraction with a highest level of schooling of ninth grade, the unemployment rate, and the fraction visible minority. We use the Enumeration Area (EA) and Dissemination Area (DA) levels of the Census. Both EA and DA are meant to represent the area that an individual Census enumerator would travel when enumerating the population, roughly 400-700 people. EA is the name of the area in 1996 and before; Statistics Canada changed the name to DA for the 2001 and future censuses. They are roughly the same areas, but do not overlap perfectly. We match EAs to DAs by taking the shortest distance between the centroids of each area. We attach census data from 1996 to all records on or before 1998, and 2001 census data to all records after 1998.
} 
From the administrator perspective, the tests are more important, as they are used to assess how individual students, schools, and districts are performing compared to other students, schools, or districts within each year and over time. The data contain information on students' raw test scores (i.e. their percentage scores) on each test. For those students who did not write the test, a variable indicates whether they were "excused"; though the test is mandatory, typically about $5 \%$ of students are excused.

The sample universe consists of 120,108 students born between May 1985 and December 1987 who are observed at entry; this group of students turns five years old around the time when dual entry was initiated in BC. Restricting the sample to those students observed at entry is key, as the identifying variation in schooling arises due to students' exposure to the dual entry program, and exposure to the program is only known for those observed in their first year. In principle, we could also use data from January 1984 to May 1985, but we exclude them for two reasons. First, we cannot identify entry dates for any students born in 1984 because they entered school before BC began collecting data on students. Second, dual entry was piloted in some districts and schools in school year 1989-1990, but because those districts are unknown to us, we cannot specify expected entry age precisely for those students. ${ }^{11}$

We examine four separate outcomes: grade repetition before age nine, grade repetition before age fifteen, and scores on a math and reading test written in grade 10. Out of the total 120,108 students in the sample universe, 112, $676(93 \%)$ are observed at age nine, 108,191 (90\%) are observed at age fifteen, and 87,320 (72\%) are observed writing both the grade 10 math and reading test. Students are lost from the sample over time mainly to normal mobility that is observed in any school system, and in the case of the test scores because the test was discontinued at the end of the 2002 school year. To ensure that attrition is not selective among the treatment or control groups in our study, we later estimate a model similar to Equation 2 to quantify the degree of differential attrition in the data.

\footnotetext{
${ }^{11} \mathrm{We}$ assess the robustness to including those students in the model and setting their expected entry dates equal to what would be observed in a single entry system. We find that the main results are robust to the inclusion of this sample
} 


\subsection{Variable Construction}

Our main outcome is a binary variable equal to one if a student has repeated any grade, except Kindergarten, prior to age nine or fifteen, respectively. ${ }^{12}$ We compute this variable by looking at each student's history and noting if they appear in the same grade twice before they reach the relevant age. We also analyze math and reading scores on the tenth grade FSA test. Because the main analysis sample is the set of students born from May 1985 through 1987, and because test scores are available starting in 1999, the only scores we observe for these students are from the tenth grade tests. Both scores are standardized to have a mean of zero and standard deviation one by grade, year, and skill among all students writing the test.

We compute exact entry age using each student's age on September 1 or January 1 (whichever is appropriate under the entry laws) in the year students were first observed in Kindergarten. Because data are collected only once each October, we are unable to obtain a precise entry age for students who were expected to start in January, 1991 and appear in the data in Kindergarten in October, 1991. A student who is observed in Kindergarten in October 1991 may have delayed entry to September, 1991, or may have actually began school in January but stayed in Kindergarten in September. Using the numbers provided in Table 2, we are able to identify an actual entry age for $78 \%$ of November-December 1985 born children, but only 6\% of January-April 1986 born children.

For students without precise observed entry ages, we assign them the average entry age based on all students in the universe who have the same expected entry age and whose actual entry age is observed. We use these imputed entry ages in the 2SLS regressions. Because the 2SLS results are based partially on imputed information, we also present reduced-form estimates whenever possible, which may be preferred choice for readers not comfortable with imputing data.

\subsection{Summary Statistics}

Figure 2 plots grade repetition rates against month of birth separately for students born in 1985, 1986, and 1987. It is clear that students born later in the year are more likely to repeat. The upper panel of the Figure shows that nine year old students born between January and April, 1986 have

\footnotetext{
${ }^{12}$ The policy itself forced January-April, 1986 born children to repeat Kindergarten. Thus, we focus on grade 1 and later to avoid counting those students.
} 
a distinctively higher grade repetition rate than students born during those same months in 1987. There does not appear to be a noticeable difference for students born in November-December, 1985 compared to students born at the same time in other years. The lower panel of that Figure shows a very similar pattern among fifteen year old students. Figure 3 repeats the same exercise, but with numeracy scores in the upper panel, and reading scores in the lower. Though there is more noise in these figures, students born in the first four months of 1986 perform worse, especially in reading, than the comparable group born in 1987.

Table 3 shows averages of the main variables within each of the treatment and control groups defined in Table 1. ${ }^{13}$ Looking first at Panel A, 6.08\% of November-December 1985 students have repeated before age 9, but the same is true for only $2.47 \%$ of the untreated May-October 1985 students. The difference of 3.61 percentage points is smaller than the 4.06 percentage point difference between the same groups in 1987, but larger than the 3.21 percentage point difference in 1986 . The implied difference in differences effect of starting school four months late for this group is therefore roughly zero.

Still in Panel A, 3.08\% of the January-April group in 1986 repeated by age nine, compared to $2.25 \%$ of the May-Oct group, a difference of 0.83 percentage points. In 1987, however, the difference between January-April and May-October is -1.10 percentage points. The implied difference in differences suggests that starting Kindergarten six months early increases the probability of repeating by 1.93 percentage points. Similar results with higher magnitudes are observed among 15 year olds in Panel B.

In Panel C we examine the subsample of tenth grade test takers. In 1985, November-December students score roughly the same on the math test as May-October students. In 1987, however, November-December students score 0.069 standard deviations worse on the math test. A difference in differences estimate $(0-(-0.069))$ then implies that starting Kindergarten late improves test scores by roughly 0.069 standard deviations. The implied difference in differences estimate for reading based on this group is 0.022 standard deviations. A difference in differences estimate of starting Kindergarten late based on comparing the January-April students to the May-October students is 0.021 for math, and 0.052 for reading.

\footnotetext{
${ }^{13}$ Averages of the full set of variables included in the regressions is in Table A1.
} 
Based on this summary data, starting Kindergarten later has a beneficial effect on grade progression and on future cognitive performance. In one sense, this is reassuring because the intention of the policy was partly to improve the performance of the students who would have been young in a single entry system (the November-December children). Unfortunately, the policy forced the larger January-April group to start earlier than normal, which has a detrimental effect on their outcomes. These estimates also imply that spending less time in Kindergarten improves future performance, results that are echoed in the formal regression analysis below. We proceed now to the regression estimates, and discuss potential explanations for this effect following the presentation of those results.

\section{Results}

\subsection{Grade Repetition}

Table 4 presents the results of the reduced form and first stage from the main specification. Column 1 estimates the overall effect entering Kindergarten one year late. Starting Kindergarten one year late reduces the probability of repeating a grade by 2.7 percentage points. Across all students born in 1987 , the grade repetition rate is roughly $3.21 \%$, so the effect of the policy increases grade repetition by $83 \%$. Symmetrically, this implies that entering Kindergarten one year early would increase grade repetition by the same amount. Column 2 generalizes the specification by interacting the birth date control with the indicators for year of birth, and treatment or control group. This allows the slope of the relationship between repetition and date of birth to vary across treatment and control groups. Estimates are slightly lower, but are generally robust to the change in specification.

Columns 3 and 4 allow the policy effect to differ across the two treatment groups by interacting the group dummies with the expected entry age variable (but excluding uninteracted expected entry age). The effect is mainly driven by the January-April group; for November-December students, the point estimate is somewhat imprecise, and drops in magnitude when a more flexible birth date control is included.

Columns 5-8 repeat the same exercise for fifteen year old students. Estimates follow a similar 
pattern, but magnitudes are higher reflecting the fact that more students will have repeated by age fifteen. Entering Kindergarten one year late reduces the probability of repeating by 3.2 to 3.7 percentage points, with most of the effect attributable to the January-April group.

Panel B reports the first stage relationship between expected entry age and actual entry age at age nine and fifteen. In columns 1-2 and 5-6, there is a very strong positive relationship overall, which suggests a high level of compliance with the rules. Note that the first stage is also a difference in differences estimator, so the results are interpreted as the difference in the relationship in the policy year and non-policy year (in the non-policy year the relationship is roughly zero when we control for date of birth). When the relationship is estimated separately for each treatment group it is clear that the relationship is strongest among the January-April group. The effect for NovemberDecember children is weaker because many students began school early, and likely many delayed entry. The Kleibergen-Paap F-Statistic testing the null of weak instruments is very high in all cases, meaning we reject soundly the null that our instrument is weak.

Table 5 reports the 2SLS results. The estimates mirror the pattern for the reduced form, but the magnitudes are slightly higher reflecting non-compliance. Starting Kindergarten one year late reduces the average nine year old's probability of repetition by between 2.8 and 3.2 percentage points, and reduces a fifteen year old's probability of repetition by between 4.1 and 4.3 percentage points. Columns 3-4 and 5-6 show that the effect is driven mainly by the January-April treatment group.

The results show that starting Kindergarten late improves student outcomes by lowering the likelihood of repeating a grade. As we discussed briefly above, this is expected in some sense because one of the goals of the policy was to improve the performance of the youngest students in the class by having them start school later to increase maturity and therefore readiness. At the same time, however, the policy reduced entry age for all January-April students, making them less mature at entry. On the other hand, absent a maturity effect, the estimates imply the counterintuitive result that less time in Kindergarten lowers the likelihood of grade repetition. One explanation for this finding is that both a maturity and Kindergarten effect exist, but the effect of improved maturity outweighs any negative impact of spending less time in Kindergarten. Because these two variables move together, there is no way to separate them in the analysis. We note, however, that this 
explanation is consistent with a large body of evidence showing that later entry has a positive effect on outcomes. ${ }^{14}$ We note in particular that our results are qualitatively similar to those Bedard and Dhuey [2009], who show that moving school entry cutoffs backward (from January to November, for example) increases wages in the future. For directly affected students (i.e. those who enter in a later year because of the change), backing up the cutoff increases absolute, relative, and average cohort age in a similar way to the November-December students in our study. Our results are therefore in line with theirs, though it should be noted that there is no concomitant change in years of kindergarten in their variation.

Also contributing to the observed positive effect of late entry is how students spend their time outside of formal schooling. Late starters presumably spent time at home or in formal daycare as they waited to enter the BC school system. If this type of care has a positive effect on their outcomes, or if Kindergarten is of low quality compared to alternative uses of time, then this would contribute to the effects we observe, and would be consistent with the results from studies such as Baker et al. [2008], Lefebvre et al. [2011] , Herbst and Tekin [2010], and to some extent Magnuson et al. [2007] who show negative effects of child care or preschool programs on behavioural and cognitive outcomes. As we explain later, the strongest effect we observe is among low-income students, which implies that alternative uses of time must be relatively much better for these students compared to higher income students. While not implausible, it seems more likely that higher income students would be enrolled in high quality day care, and that they would benefit the most from that compared to formal Kindergarten. Thus, perhaps the maturity explanation is accurate.

Because our estimates are generated from a unique policy experiment, and because our estimates are LATEs, there is some question about external validity. On one hand, the policy simply extends or shortens time spent in a Kindergarten program, and so it is not quite like estimating the effect of implementing Kindergarten. Furthermore, the policy took what would have been a cohesive entry cohort and split them up in an unusual way that changed potentially important variables like

\footnotetext{
${ }^{14}$ Estimates for BC in particular are in Smith [2009]; for other jurisdictions, see Bedard and Dhuey [2006], Elder and Lubotsky [2009], and McEwan and Shapiro [2008]. The interpretation of our estimates is fundamentally different from this literature. Entry age is identically linked to schooling and "test age" through the following equation: $A T=A E+S$. Most entry age studies use variation in entry age either within a single-entry cohort or across the boundary at the cutoff point. This type of variation implicitly holds schooling (S) constant, so entry age (AE) is perfectly collinear with variation in test age (AT). Our variation, on the other hand, holds test age constant and varies entry age and schooling at the same time.
} 
peer composition and the relative age structure in addition to time spent in school. Finally, there was non-compliance (especially among November-December students), so if there are heterogeneous

treatment effects, we might be identifying from a select subgroup of students. On the other hand, the results are more generalizable than targeted programs such as Head Start, and the overall population in $\mathrm{BC}$ is comparable to other jurisdictions in Canada and the United States. Thus, the variation we use does have some benefits and some drawbacks; overall, we feel that our results are useful in predicting the potential effects of introducing or extending pre-k and Kindergarten programs.

\subsection{Test Scores}

In this section we use tenth grade test scores as the outcome. Results in this section must be interpreted cautiously because they could depend on prior outcomes of the policy. We have seen previously that entering Kindergarten one year late reduces the probability of grade repetition. If repetition has an effect on test scores, the regressions below will pick up partly the effect of the policy on test scores, and partly the effect of grade repetition. These main results might therefore be interpreted as net of the effect of grade repetition. In the next section of the paper, we discuss estimates separated by student income quartile, which partially circumvents the grade repetition effect because students in the upper quartile show a lower effect of the policy on repetition. We return to these estimates below.

Table 6 shows the reduced form and first stage effect with math and reading scores as outcomes. Similar to the previous section, we present the overall effect on the policy, and then separate by treatment group. Even numbered columns present results where the birth date control is interacted with the group and birth year dummies, while odd numbered columns do not perform this interaction. In Panel A, Column 1 reports the results from Equations 1 and 2. Results show that entering Kindergarten 1 year late improves test scores by 0.038 standard deviations in math, and column 5 shows a positive effect on reading of 0.076 percentage points. When we specify a more flexible control for birth date in columns 2 and 6, the effect sizes rise to 0.068 and 0.110 , respectively. Estimating separately for each treatment group, we see that the effect is similar in both math and 
reading, though the December-November estimates are less precise, especially for math. Panel B shows a strong first stage, and F-statistics on the excluded instruments that are very high. Note that the first stages in math and reading are identical.

In Table 7 we report the 2SLS estimates of the effect of the policy on math and reading scores. Estimates echo the reduced form coefficients reported in the previous table, but at a slightly higher magnitude, reflecting the non-compliance with the policy. Entering Kindergarten on year late improves math scores by 0.045-0.089 standard deviations in math, an 0.090 and 0.144 standard deviations in reading.

The effect of the policy on cognitive achievement supports the grade repetition results: entering one year late improves cognitive performance significantly at the end of high school. The implication is that the policy has long lasting effects on students, and may affect outcomes beyond high school into university or perhaps the labour force, though we do not test those hypotheses in this paper. Our explanation for this result is identical to the one provided for the grade repetition results. The caveat is that the effect of the policy might be partly operating through grade repetition. More specifically, we know that entering school later reduces the probability of repetition, and if lower grade repetition improves test scores, our estimates in test score regressions might be too high.

\subsection{Subgroup Analysis}

In this section we break the sample up into groups defined by the income quartile of the neighbourhood where a student resides, and separately by gender. We choose to break the estimates up by income and gender because estimates across these subgroups address important questions. Policy makers might be particularly interested in the effects on lower income students. Furthermore, gender differences in educational outcomes are receiving an increasing amount of press, especially concerning troubles faced by boys; we therefore find it important to present separate estimates by gender. ${ }^{15}$

Table 8 presents the reduced form and 2SLS estimates with grade repetition as the outcome. Column 1 of Panel A shows that entering Kindergarten late reduces the probability of repetition

\footnotetext{
${ }^{15} \mathrm{~A}$ series in the national Canadian newspaper The Globe and Mail provides a good summary of the issue. See http://www.theglobeandmail.com/news/national/time-to-lead/failing-boys
} 
by 3.2 percentage points for students in the lowest income quartile. The magnitude of the effect declines across the income quartiles to 1.3 percentage points for students in the highest income quartile. A similar pattern is observed in Panel B, which presents the reduced form for fifteen year olds, and in the 2SLS estimates in Panels C and D.

For the sample of nine year olds, the reduced form effect of entering Kindergarten late is a reduction of 3.3 percentage points for males, and 2.0 percentage points for females. By age fifteen, however, the effects are roughly equal at 3.7 percentage points. Again, the 2SLS estimates in Panels $\mathrm{C}$ and $\mathrm{D}$ show the same pattern with higher magnitudes.

Table 9 shows the subgroup estimates for test scores. Panel A shows that across-quartile effects for math are all imprecisely estimated and do not show a distinctive pattern. Panel B shows that for reading the effect is strongest and most precisely estimated for students in the lowest income quartile. For this group, entering Kindergarten late improves cognitive performance by 0.095 standard deviations. 2SLS estimates in panels C and D are similar to the reduced form. ${ }^{16}$

Arguably the most important group are the low income students because they are the most at risk for poor outcomes in the future. The results above suggest that entering kindergarten late is more beneficial for them compared to higher income students in terms of both grade repetition and reading scores. This result is consistent with Lefebvre et al. [2011], who shows a strong negative effect of Quebec's child care policy on low educated mothers. This could mean that spending time at home is more important for these students, but such an explanation seems unlikely. An alternative explanation is that lower income students benefit from starting later because they are more ready simply through the ageing process, whereas ageing would not be as beneficial to higher income students who have other ways to prepare them for school - like quality child care - available to them.

Recall that the test score estimates presented in Table 7 had to be interpreted cautiously because the policy effect might be confounded by grade repetition. The results in Table 9 lend some support to that theory. The policy effect on grade repetition and test scores is strongest among

\footnotetext{
${ }^{16}$ Note that there is no evidence that compliance with the entry laws differs appreciably across income quartiles. Using 1987 data only, we estimate that $1.79 \%$ of income quartile 1 students, $1.96 \%$ of quartile 2 students, $1.44 \%$ of quartile 3 students, and $1.72 \%$ of quartile 4 students do not comply with the rules. On the other hand, $2.14 \%$ of males and $1.29 \%$ of females fail to comply
} 
low income students, and at least for reading, weakest among the highest income students. Thus the confounding effect of grade repetition is smallest among the high income students, and for that group entering Kindergarten late improves reading test scores 0.086 standard deviations, and math scores by up to 0.05 standard deviations. We might then think of these estimates as the cleanest estimates of the potential effect of the policy, and they are negative but at smaller magnitudes. The problem, however, is that neither the math nor reading coefficient is precisely estimated. Of course, it is entirely possible that none of the results are confounded and the main effect we estimated is indeed an accurate effect of the policy. ${ }^{17}$

\subsection{Attrition}

Our analysis is contingent on following a set of Kindergarten entrants over time until they reach age nine and fifteen, and when they write a tenth grade standardized test. Over time it is natural for some students to exit the school system because they leave the province, and we would not expect this to affect our results. It is possible, however, that some non-random group of students exit the province because of the policy itself. This latter form of attrition is problematic and could bias our results because treatment and control groups would then not be comparable.

We check for selective attrition with the following specification

$$
I S_{i}=\gamma_{0}+\gamma_{1} d_{85}+\gamma_{2} d_{86}+\gamma_{3} d_{J A}+\gamma_{4} d_{N D}+\gamma_{5}\left(d_{85} \times d_{N D}\right)+\gamma_{6}\left(d_{86} \times d_{J A}\right)+\gamma_{7} b d_{i}+\xi_{i}
$$

where the analysis sample is all 120,108 students observed at entry, and $I S_{i t}$ is equal to 1 if the student is in the sample at age nine, fifteen, or at test time. All other variables are defined as before. The coefficient $\gamma_{5}$ tells us if there is any differential likelihood of being in the sample for the November-December group (relative to May-October) in 1985 versus other years, and $\gamma_{6}$ does the same for the January-April group. This specification is similar to Equation 2, but we do not use the

\footnotetext{
${ }^{17}$ We also estimated quantile regressions for the reduced form specification for test scores at the $0.1,0.5$ and 0.9 quantiles. For math, the effects were 0.026 at the 0.1 quantile, -0.002 at the 0.5 quantile, and 0.063 at the 0.9 quantile. For reading the effects were 0.042 at the 0.1 quantile, 0.065 at the 0.5 quantile, and 0.087 at the 0.9 quantile. These estimates suggest an increasing effect of the policy as we move up the test score distribution. The effects, however, are quantitatively in the same general range as the income estimates. Note that quantile regressions are not estimated for the grade repetition outcome because of convergence problems
} 
entry age variable directly because we are only interested in the raw differences in the probability of being in the sample.

The coefficients on the interaction terms in columns 1 and 2 of Table 10 show some small differences in the probability of being in the sample at age nine.Students in each of the treatment groups are actually slightly more likely to be in the sample, so if anything there is a differential drop in attrition among the treated students. The point estimates, though precise, are small and below 1.5 percentage points. In columns 3 and 4 , there is not much difference at age fifteen, and in fact treated students are even more likely to be in the sample relative to the controls. As additional evidence that attrition is not problematic for these groups, Figure 4 plots the probability of being in the sample for students born on each day during the sample period. There is no distinguishable pattern that could be caused by attrition.

In terms of the likelihood of taking the grade 10 tests, the story is different. The most notable difference is that treated November-December students are 5.2 percentage points more likely to take the test versus May-October students. This large difference arises entirely because the NovemberDecember 1987 students are the final entry cohort to be eligible to take the test (because it was discontinued in 2002). Thus, only on-time students born in 1987 take the test, and since NovemberDecember students are much less likely to be on time in any year, this creates a large drop in the probability of taking the test for this group. This pattern is summarized in Figure 4, which plots the probability of taking the grade 10 test against date of birth. Note the large drop in the fraction of students taking the test in November-December, 1987. On the other hand, there is no evidence from this figure that in 1985 alone November-December children are significantly more or less likely to take the test.

Based on these results, we do not see attrition as a significant issue. In particular the loss of many likely weak students at the end of 1987 is not concerning because the test score results are driven mostly by the January-April born students, who are not affected by attrition as much. 


\subsection{Robustness}

Our first robustness check, interacting the birth date control with the group variables, has already been reported and we noted that results are generally robust to this change in specification. We also check the robustness of our results by including the sample of students born in 1984 and early 1985 and reestimating the reduced-form version of our main results. For this exercise we code expected entry age to be equal to what we would observe in a single entry system. This is not entirely correct because dual entry was piloted in the year 1984 students began Kindergarten, but since the program was optional and only offered in a few districts, it is likely that takeup was low. Therefore, assuming entry dates under a single entry system is a reasonable approximation to the true expected entry dates. Table 11 shows that regardless of the dependent variable used, adding these students to our sample does not change the main results appreciably, except to lower standard errors on the estimates.

In results available upon request, we also reestimate our main results with a set of school fixed effects. This would control for school-level differences that might be related to the policy itself, since schools did have some discretion in the way in which they dealt with dual entry students. Adding these extra controls has no meaningful impact on the results.

\section{Conclusion}

Early childhood education is important for the development of human capital, and Kindergarten is arguably the most widespread early childhood program. Early learning can establish a base upon which children will build as they age, and the more solid the base the easier it will be to accumulate human capital in the future. In this paper, we examined a unique policy experiment that simultaneously altered students' school start ages and the amount of time they spent in early education. We found that students entering Kindergarten later lowered their likelihood of repeating future grades, and improved their performance on standardized tests in the tenth grade. The larger effects are observed for lower income students and males.

Our results are somewhat counterintuitive because they imply that spending less time in Kindergarten improves future outcomes. Nevertheless, they are consistent with some parts of the literature, 
in particular Bedard and Dhuey [2009] who examine the effect of rolling back school entry dates, which is similar in many ways to the policy we examine here. In our study, we examine variation that is a combination of two fundamentally inseparable effects: an entry age or maturity effect, and a time in school effect. The most likely explanation for our results is that the effect of increased school readiness from starting one year later dominates the time in school effect. Alternatively, part of the effect can be explained by what children do with their time when they are not in Kindergarten. If they are enrolled in quality day care or if time spent at home is more beneficial to their learning, then this will improve the performance of late starters. 


\section{References}

Baker, Michael, Jonathan Gruber, and Kevin Milligan (2008) 'Universal child care, maternal labor supply, and family well-being.' The Journal of Political Economy 116(4), 709-745

Balcom, Susan (October 5, 1992) 'Dual-entry passed over as parents concerned.' In 'The Vancouver Sun'

Bedard, Kelly, and Elizabeth Dhuey (2006) 'The persistence of early childhood maturity: International evidence of long-run age effects.' The Quarterly Journal of Economics 121(4), 1437-1472

_ (2009) 'School entry policies and skill accumulation across directly and indirectly affected men.' Mimeo

Bula, Frances (July 24, 1991b) 'January starters a dilemma.' In 'The Vancouver Sun'

_ (May 31, 1991a) 'Hagen kills dual entry: Mixed reacion to end of twice-a-year admittance.' In 'The Vancouver Sun'

Cannon, Jill S., Alison Jacknowitz, and Gary Painter (2006) 'Is full better than half? examining the longitudinal effects of full-day kindergarten attendance.' Journal of Policy Analysis and Management 25(2), 299-321

Cascio, Elizabeth, and Diane Whitmore Schanzenbach (2007) 'First in the class? age and the education production function.' Working Paper 13663, National Bureau of Economic Research, December

Cascio, Elizabeth U. (2009) 'Do investments in universal early education pay off? long-term effects of introducing kindergartens into public schools.' Working Paper 14951, National Bureau of Economic Research, May

Cooper, Harris, Ashley Batts Allen, Erika A. Patall, and Amy L. Dent (2010) 'Effects of full-day kindergarten on academic achievement and social development.' Review of Educational Research $80(1), 34-70$

Cunha, Flavio, James J. Heckman, and Lance Lochner (2006) 'Interpreting the evidence on life cycle skill formation.' In Handbook of the Economics of Education, ed. Erik Hanushek and F. Welch, vol. 1 (Elsevier) chapter 12, pp. 697-812

Currie, Janet (2001) 'Early childhood education programs.' Journal of Economic Perspectives $15(2), 213-238$

Currie, Janet, and Duncan Thomas (1995) 'Does head start make a difference?' American Economic Review 85(3), 341-64

_ (1999) 'Does head start help hispanic children?' Journal of Public Economics 74(2), 235-262

DeCicca, Philip (2007) 'Does full-day kindergarten matter? evidence from the first two years of schooling.' Economics of Education Review 26(1), 67-82

Dhuey, Elizabeth (Forthcoming) 'Who benefits from kindergarten? evidence from the introduction of state subsidization.' Educational Evaluation and Policy Analysis 
Dubois, Wendy (January 11, 1992) 'No limbo for dual-entry students.' In 'The Vancouver Sun'

Editorial (July 25, 1991) 'Children's interests must come first.' In 'The Vancouver Sun'

Elder, Todd E., and Darren H. Lubotsky (2009) 'Kindergarten entrance age and childrenâ ${ }^{\mathrm{TM}_{\mathrm{S}}}$ achievement: Impacts of state policies, family background, and peers.' Journal of Human Resources

Fitzpatrick, Maria D (2008) 'Starting school at four: The effect of universal pre-kindergarten on children's academic achievement.' The B.E. Journal of Economic Analysis and Policy

Garces, Eliana, Duncan Thomas, and Janet Currie (2002) 'Longer-term effects of head start.' American Economic Review 92(4), 999-1012

Gormley, William T., and Ted Gayer (2005) 'Promoting school readiness in oklahoma: An evaluation of tulsa's pre-k program.' The Journal of Human Resources 40(3), 533-558

Gray-Grant, Jennifer (August 31, 1991) 'The problem of portables: When half a million kids get back to school, there won't be much elbow room.' In 'The Vancouver Sun'

_ (January 3, 1992) 'End of dual entry leaves parents, children searching for right direction.' In 'The Vancouver Sun'

Herbst, Chris M., and Erdal Tekin (2010) 'The impact of child care subsidies on child well-being: Evidence from geographic variation in the distance to social service agencies.' NBER Working Papers 16250, National Bureau of Economic Research, Inc, August

Lefebvre, Pierre, Philip Merrigan, and Francis Roy-Desrosiers (2011) 'Quebec's childcare universl low fees policy 10 years after: Effects, costs, and benefits.' Working Paper 11-01, Centre Interuniversitaire sur le Risque, les Politiques Economiques et l'Emploi, January

Ludwig, Jens, and Douglas L. Miller (2008) 'Does head start improve children's life chances? evidence from a regression discontinuity design.' The Quarterly Journal of Economics 122(1), 159208

Magnuson, Katherine A., Christopher Ruhm, and Jane Waldfogel (2007) 'Does prekindergarten improve school preparation and performance?' Economics of Education Review 26(1), 33 - 51

McEwan, Patrick J., and Joseph S. Shapiro (2008) 'The benefits of delayed primary school enrollment: Discontinuity estimates using exact birth dates.' Journal of Human Resources

McTavish, Marianne (1990) 'Dual entry in b.c. kindergartens.' Prime Areas

Rees, Ann (May 31, 1991) 'Dual entry scrapped: Parents applaud victoria flip-flop.' In 'The Province'

Smith, Justin (2009) 'Can regression discontinuity help answer an age-old question in education? the effect of age on elementary and secondary school achievement.' The B.E. Journal of Economic Analysis \& Policy

Walston, Jill, and Jerry West (2004) 'Full-day and half-day kindergarten in the united states: Findings from the early childhood longitudinal study, kindergarten class of 1998-1999.' Technical Report, U.S. Department of Education, National Centre for Education Statistics 
Table 1: Assignment to Treatment and Control Groups

\begin{tabular}{llll}
\hline \hline Birth Month & & Birth Year & \\
\hline \multirow{3}{*}{ Jan-Apr } & 1985 & 1986 & 1987 \\
\cline { 2 - 4 } May-Oct & Not in Sample & Treatment & Control \\
Nov-Dec & Control & Control & Control \\
\hline \hline
\end{tabular}

Table 2: Counts of Students by Year and Grade of Entry

\begin{tabular}{|c|c|c|c|c|}
\hline \multirow[b]{3}{*}{ Grade of First Observation } & \multicolumn{2}{|c|}{1985 Birth Cohort } & \multicolumn{2}{|c|}{1987 Birth Cohort } \\
\hline & \multicolumn{4}{|c|}{ Year of First Observation } \\
\hline & 1990 & 1991 & 1992 & 1993 \\
\hline $\mathrm{K}$ & 2124 & 1552 & 6406 & 503 \\
\hline 1 & 0 & 3512 & 0 & 0 \\
\hline \multicolumn{5}{|c|}{ "Panel B: January-April Births } \\
\hline & \multicolumn{2}{|c|}{1986 Birth Cohort } & \multicolumn{2}{|c|}{1987 Birth Cohort } \\
\hline & \multicolumn{4}{|c|}{ Year of First Observation } \\
\hline Grade of First Observation & 1991 & 1992 & 1992 & 1993 \\
\hline$\overline{\mathrm{K}}$ & 13347 & small & 14600 & small \\
\hline 1 & 797 & 0 & 0 & 0 \\
\hline
\end{tabular}

Notes: Cells represent counts of students observed at entry. In Panel B, "small" refers to a low student count; the actual number of students is suppressed to protect confidentiality. 
Table 3: Average Student Characteristics

\begin{tabular}{|c|c|c|c|c|c|c|c|c|}
\hline & \multicolumn{2}{|c|}{1985} & \multicolumn{3}{|c|}{1986} & \multicolumn{3}{|c|}{1987} \\
\hline & $\begin{array}{l}\text { May- } \\
\text { Oct }\end{array}$ & $\begin{array}{l}\text { Nov- } \\
\text { Dec }\end{array}$ & $\begin{array}{l}\text { Jan- } \\
\text { Apr }\end{array}$ & $\begin{array}{l}\text { May- } \\
\text { Oct }\end{array}$ & $\begin{array}{l}\text { Nov- } \\
\text { Dec }\end{array}$ & $\begin{array}{l}\text { Jan- } \\
\text { Apr }\end{array}$ & $\begin{array}{l}\text { May- } \\
\text { Oct }\end{array}$ & $\begin{array}{l}\text { Nov- } \\
\text { Dec }\end{array}$ \\
\hline $\begin{array}{l}\text { Panel A: Age } 9 \\
\text { Repeat }\end{array}$ & 2.466 & 6.076 & 3.079 & 2.248 & 5.458 & 1.126 & 2.221 & 6.283 \\
\hline Exp Entry Age & 5.093 & 5.088 & 4.836 & 5.093 & 4.753 & 5.503 & 5.098 & 4.755 \\
\hline Actual Entry Age & 5.119 & 5.136 & 4.837 & 5.100 & 4.844 & 5.502 & 5.106 & 4.826 \\
\hline Panel B: Age 15 & & & & & & & & \\
\hline Repeat & 8.058 & 12.376 & 8.814 & 7.869 & 11.686 & 6.024 & 7.806 & 12.498 \\
\hline Exp Entry Age & 5.093 & 5.088 & 4.836 & 5.093 & 4.753 & 5.502 & 5.098 & 4.756 \\
\hline Actual Entry Age & 5.118 & 5.135 & 4.837 & 5.100 & 4.843 & 5.502 & 5.106 & 4.826 \\
\hline Panel C: Test Scc & & & & & & & & \\
\hline Math Score & -0.048 & -0.045 & -0.011 & -0.034 & -0.063 & 0.018 & -0.026 & -0.043 \\
\hline Reading Score & 0.059 & 0.044 & 0.090 & 0.060 & 0.014 & 0.140 & 0.059 & 0.021 \\
\hline Exp Entry Age & 5.092 & 5.088 & 4.836 & 5.094 & 4.753 & 5.502 & 5.099 & 4.758 \\
\hline Actual Entry Age & 5.113 & 5.118 & 4.835 & 5.100 & 4.838 & 5.500 & 5.099 & 4.763 \\
\hline
\end{tabular}

Notes: Repeat is the fraction repeating. Exp entry age is entry age according to the school entry rules, which may differ from actual entry age. Test scores are reported as $z$-scores, standardized across all students writing the math and reading test in a give year, respectively. 


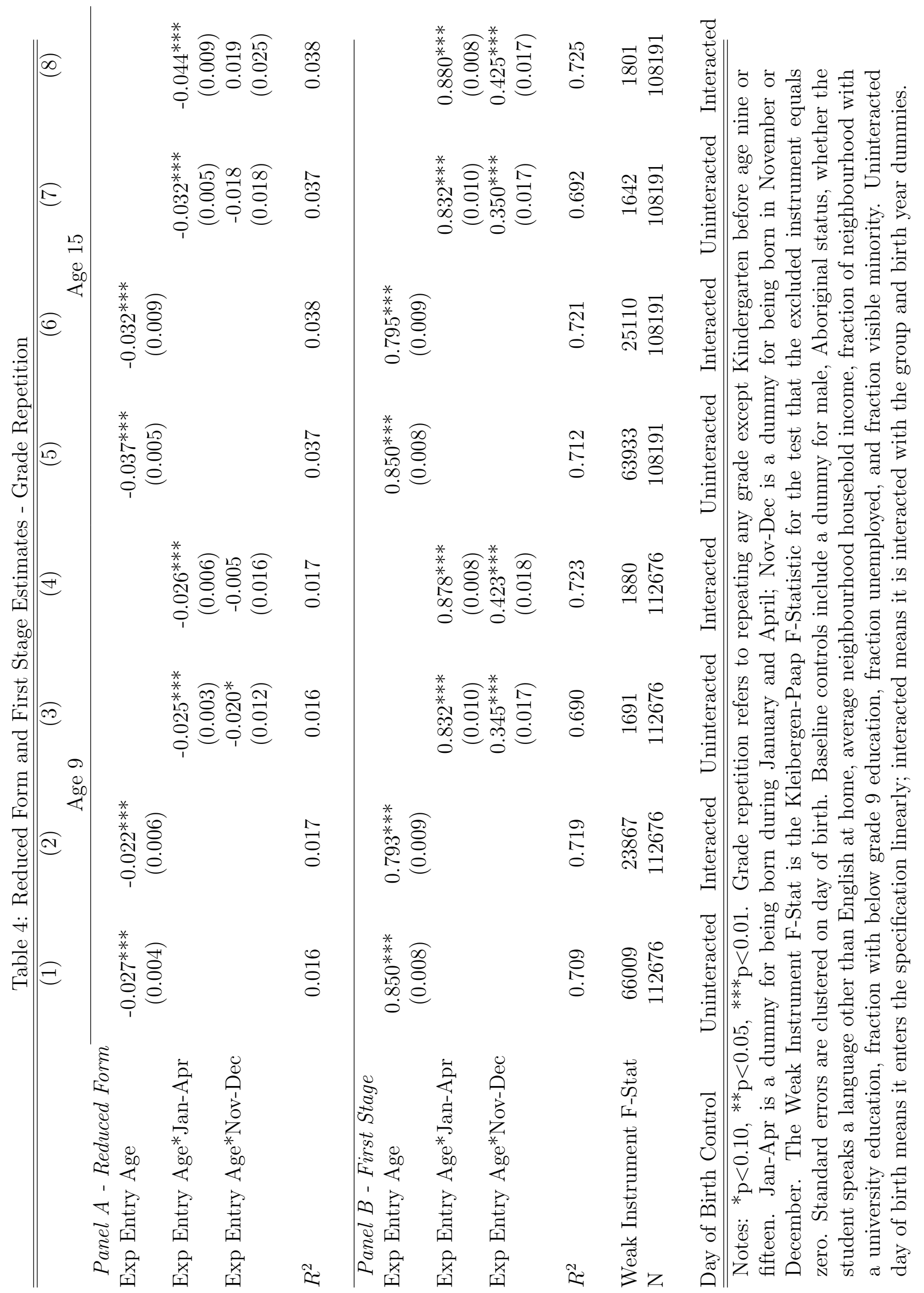




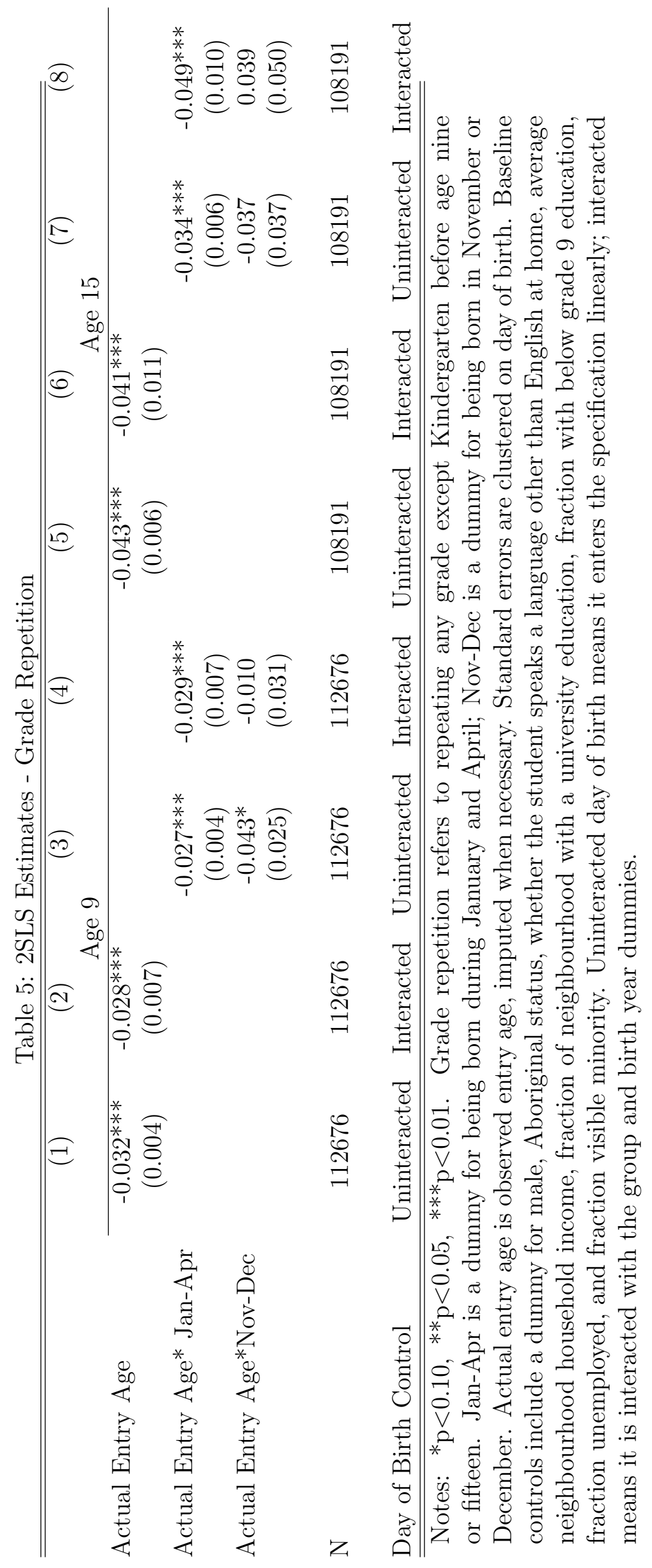




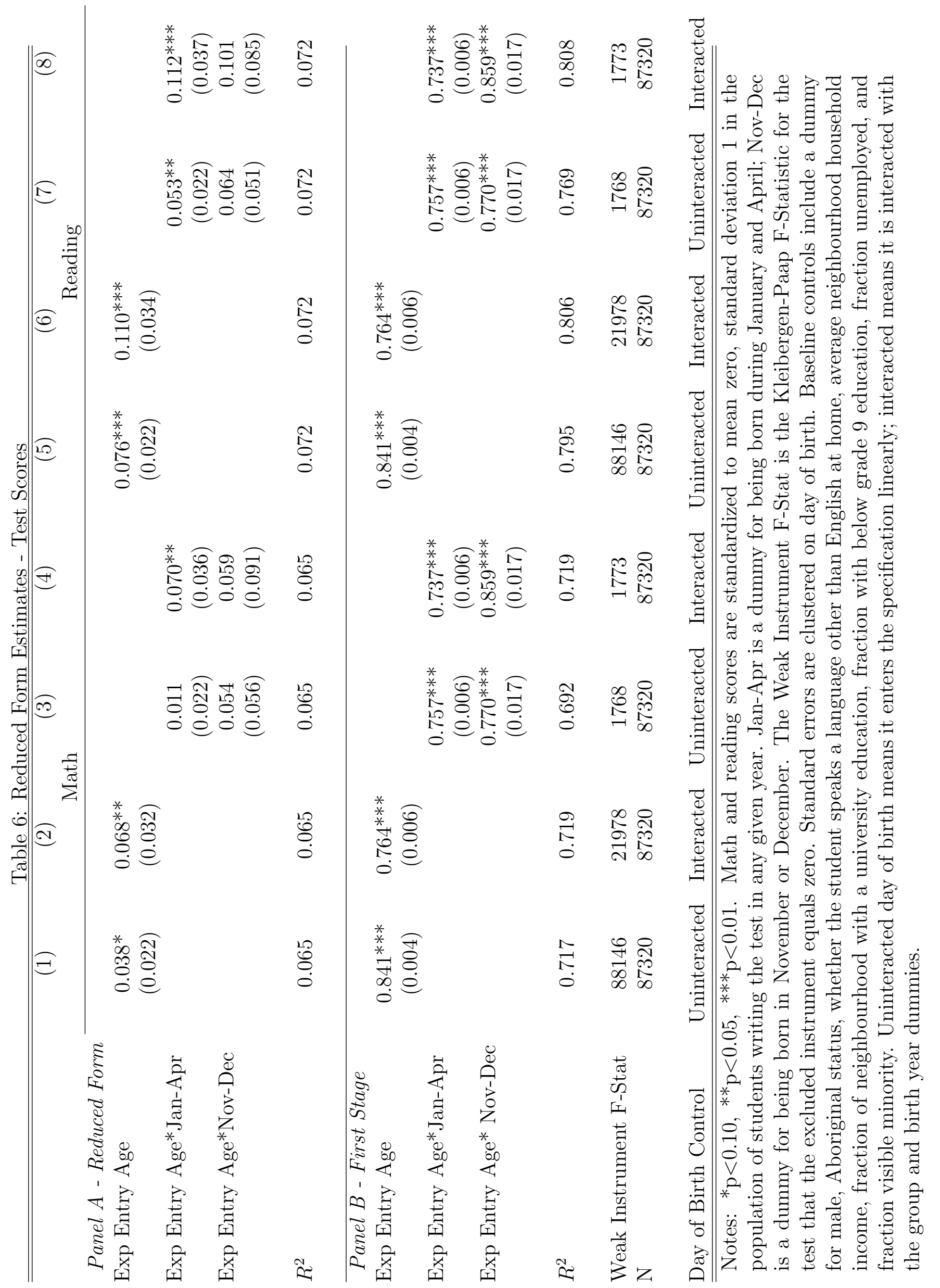




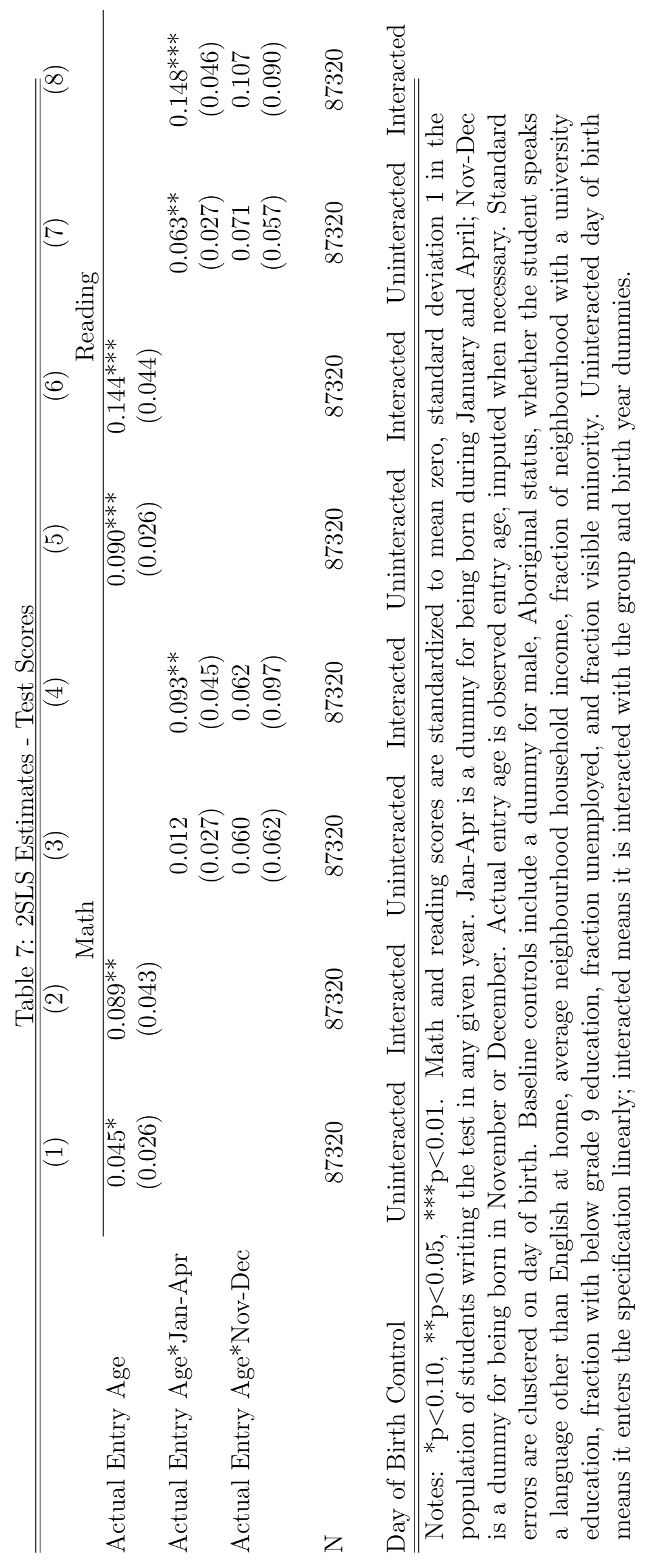


Table 8: 2SLS and Reduced Form Estimates - Grade Repetition, by Income Quartile and Gender

\begin{tabular}{|c|c|c|c|c|c|c|}
\hline & (1) & $(2)$ & (3) & (4) & $(5)$ & (6) \\
\hline & Q1 & Q2 & Q3 & Q4 & Male & Female \\
\hline \multicolumn{7}{|c|}{ Panel A: Age 9 Reduced Form } \\
\hline Exp Entry Age & $\begin{array}{c}-0.032^{* * *} \\
(0.007)\end{array}$ & $\begin{array}{c}-0.027^{* * * *} \\
(0.007)\end{array}$ & $\begin{array}{c}-0.037^{* * *} \\
(0.007)\end{array}$ & $\begin{array}{c}-0.013^{* *} \\
(0.006)\end{array}$ & $\begin{array}{c}-0.033^{* * *} \\
(0.006)\end{array}$ & $\begin{array}{c}-0.020^{* * *} \\
(0.004)\end{array}$ \\
\hline$R^{2}$ & 0.016 & 0.015 & 0.016 & 0.014 & 0.018 & 0.009 \\
\hline $\mathrm{N}$ & 28139 & 28232 & 28128 & 28177 & 57547 & 55129 \\
\hline \multicolumn{7}{|c|}{ Panel B: Age 15 Reduced Form } \\
\hline Exp Entry Age & $\begin{array}{c}-0.056^{* * *} \\
(0.013)\end{array}$ & $\begin{array}{c}-0.038^{* * *} \\
(0.012)\end{array}$ & $\begin{array}{c}-0.027^{* *} \\
(0.010)\end{array}$ & $\begin{array}{c}-0.026^{* * *} \\
(0.010)\end{array}$ & $\begin{array}{c}-0.037^{* * *} \\
(0.009)\end{array}$ & $\begin{array}{c}-0.036^{* * *} \\
(0.007)\end{array}$ \\
\hline$R^{2}$ & 0.042 & 0.039 & 0.027 & 0.030 & 0.040 & 0.035 \\
\hline $\mathrm{N}$ & 27412 & 27318 & 26666 & 26795 & 55401 & 52790 \\
\hline \multicolumn{7}{|l|}{ Panel C: Age 9 2SLS } \\
\hline Actual Entry Age & $\begin{array}{c}-0.037^{* * *} \\
(0.008)\end{array}$ & $\begin{array}{c}-0.031^{* * *} \\
(0.008)\end{array}$ & $\begin{array}{c}-0.043^{* * *} \\
(0.008)\end{array}$ & $\begin{array}{c}-0.016^{* *} \\
(0.007)\end{array}$ & $\begin{array}{c}-0.039^{* * *} \\
(0.007)\end{array}$ & $\begin{array}{c}-0.024^{* * *} \\
(0.005)\end{array}$ \\
\hline Weak Instrument F-Stat & 17603 & 15282 & 17375 & 16159 & 30141 & 36459 \\
\hline $\mathrm{N}$ & 28139 & 28232 & 28128 & 28177 & 57547 & 55129 \\
\hline \multicolumn{7}{|l|}{ Panel D: Age 15 2SLS } \\
\hline Actual Entry Age & $\begin{array}{c}-0.065^{* * *} \\
(0.015)\end{array}$ & $\begin{array}{c}-0.044^{* * *} \\
(0.014)\end{array}$ & $\begin{array}{c}-0.031^{* *} \\
(0.012)\end{array}$ & $\begin{array}{c}-0.031^{* * *} \\
(0.012)\end{array}$ & $\begin{array}{c}-0.044^{* * *} \\
(0.010)\end{array}$ & $\begin{array}{c}-0.042^{* * *} \\
(0.008)\end{array}$ \\
\hline Weak Instrument F-Stat & 585 & 512 & 378 & 238 & 29307 & 37635 \\
\hline $\mathrm{N}$ & 27412 & 27318 & 26666 & 26795 & 55401 & 52790 \\
\hline
\end{tabular}

Notes: ${ }^{*} \mathrm{p}<0.10,{ }^{* *} \mathrm{p}<0.05,{ }^{* * *} \mathrm{p}<0.01$. Grade repetition refers to repeating any grade except Kindergarten before age nine or fifteen. Jan-Apr is a dummy for being born during January and April; Nov-Dec is a dummy for being born in November or December. The Weak Instrument F-Stat is the Kleibergen-Paap F-Statistic for the test that the excluded instrument equals zero. Q1-Q4 refers to income quartiles 1 to 4. Standard errors are clustered on day of birth. Baseline controls include a dummy for male, Aboriginal status, whether the student speaks a language other than English at home, average neighbourhood household income, fraction of neighbourhood with a university education, fraction with below grade 9 education, fraction unemployed, and fraction visible minority. Day of birth is uninteracted in all regressions. 
Table 9: 2SLS and Reduced Form Estimates - Test Scores, by Income Quartile and Gender

\begin{tabular}{|c|c|c|c|c|c|c|}
\hline & (1) & $(2)$ & $\begin{array}{l}(3) \\
03\end{array}$ & (4) & 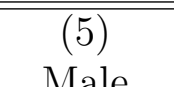 & $\begin{array}{c}(6) \\
\text { Female }\end{array}$ \\
\hline \multicolumn{7}{|c|}{ Panel A: MathReduced Form } \\
\hline Exp Entry Age & $\begin{array}{c}0.013 \\
(0.043)\end{array}$ & $\begin{array}{c}0.070 \\
(0.047)\end{array}$ & $\begin{array}{c}0.004 \\
(0.047)\end{array}$ & $\begin{array}{c}0.041 \\
(0.045)\end{array}$ & $\begin{array}{c}0.042 \\
(0.032)\end{array}$ & $\begin{array}{c}0.029 \\
(0.031)\end{array}$ \\
\hline$R^{2}$ & 0.001 & 0.001 & 0.001 & 0.001 & 0.001 & 0.001 \\
\hline $\mathrm{N}$ & 21977 & 21976 & 21667 & 21700 & 43880 & 43440 \\
\hline \multicolumn{7}{|c|}{ Panel B: Reading Reduced Form } \\
\hline Exp Entry Age & $\begin{array}{c}0.095^{* *} \\
(0.046)\end{array}$ & $\begin{array}{l}0.088^{*} \\
(0.050)\end{array}$ & $\begin{array}{c}0.031 \\
(0.044)\end{array}$ & $\begin{array}{c}0.071 \\
(0.045)\end{array}$ & $\begin{array}{c}0.099^{* * *} \\
(0.032)\end{array}$ & $\begin{array}{l}0.054^{*} \\
(0.031)\end{array}$ \\
\hline$R^{2}$ & 0.002 & 0.002 & 0.001 & 0.002 & 0.001 & 0.003 \\
\hline$N$ & 21977 & 21976 & 21667 & 21700 & 43880 & 43440 \\
\hline \multicolumn{7}{|l|}{ Panel C: Math 2SLS } \\
\hline Actual Entry Age & $\begin{array}{c}0.015 \\
(0.049)\end{array}$ & $\begin{array}{c}0.083 \\
(0.057)\end{array}$ & $\begin{array}{c}0.005 \\
(0.057)\end{array}$ & $\begin{array}{c}0.050 \\
(0.055)\end{array}$ & $\begin{array}{c}0.049 \\
(0.037)\end{array}$ & $\begin{array}{c}0.035 \\
(0.038)\end{array}$ \\
\hline Weak Instrument F-Stat & 22183 & 23229 & 22484 & 20921 & 41636 & 47703 \\
\hline $\mathrm{N}$ & 21977 & 21976 & 21667 & 21700 & 43880 & 43440 \\
\hline \multicolumn{7}{|l|}{ Panel B: Reading $2 S L S$} \\
\hline Actual Age & $\begin{array}{c}0.108^{* *} \\
(0.052)\end{array}$ & $\begin{array}{l}0.105^{*} \\
(0.060)\end{array}$ & $\begin{array}{c}0.038 \\
(0.054)\end{array}$ & $\begin{array}{c}0.086 \\
(0.055)\end{array}$ & $\begin{array}{c}0.115^{* * *} \\
(0.037)\end{array}$ & $\begin{array}{l}0.066^{*} \\
(0.037)\end{array}$ \\
\hline Weak Instrument F-Stat & 22183 & 23229 & 22484 & 20921 & 41636 & 47703 \\
\hline $\mathrm{N}$ & 21977 & 21976 & 21667 & 21700 & 43880 & 43440 \\
\hline
\end{tabular}

Notes: ${ }^{*} \mathrm{p}<0.10,{ }^{* *} \mathrm{p}<0.05,{ }^{* * *} \mathrm{p}<0.01$. Math and reading scores are standardized to mean zero, standard deviation 1 in the population of students writing the test in any given year. Jan-Apr is a dummy for being born during January and April; Nov-Dec is a dummy for being born in November or December. The Weak Instrument F-Stat is the Kleibergen-Paap F-Statistic for the test that the excluded instrument equals zero. Q1-Q4 refers to income quartiles 1 to 4 . Standard errors are clustered on day of birth. Baseline controls include a dummy for male, Aboriginal status, whether the student speaks a language other than English at home, average neighbourhood household income, fraction of neighbourhood with a university education, fraction with below grade 9 education, fraction unemployed, and fraction visible minority. Day of birth is uninteracted in all regressions. 
Table 10: Probability of Students Remaining in The Sample

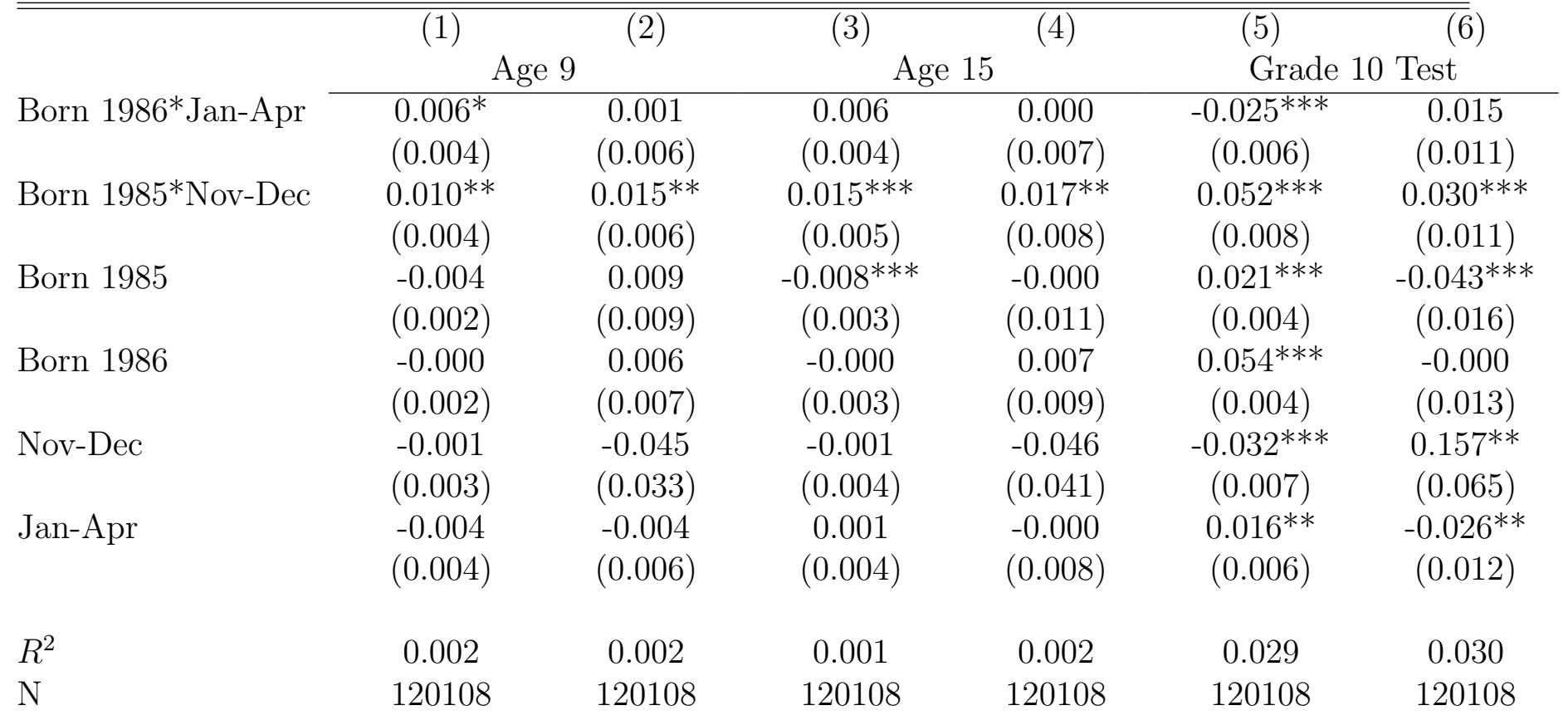

Day of Birth Uninteracted Interacted Uninteracted Interacted Uninteracted Interacted

Notes: ${ }^{*} \mathrm{p}<0.10,{ }^{* *} \mathrm{p}<0.05,{ }^{* * *} \mathrm{p}<0.01$. Born $1985 / 1986$ is a dummy for being born in 1985/1986. Jan-Apr is a dummy for being born between January and April; Nov-Dec is a dummy for being born in November or December. Standard errors on coefficients are clustered on birth date. 


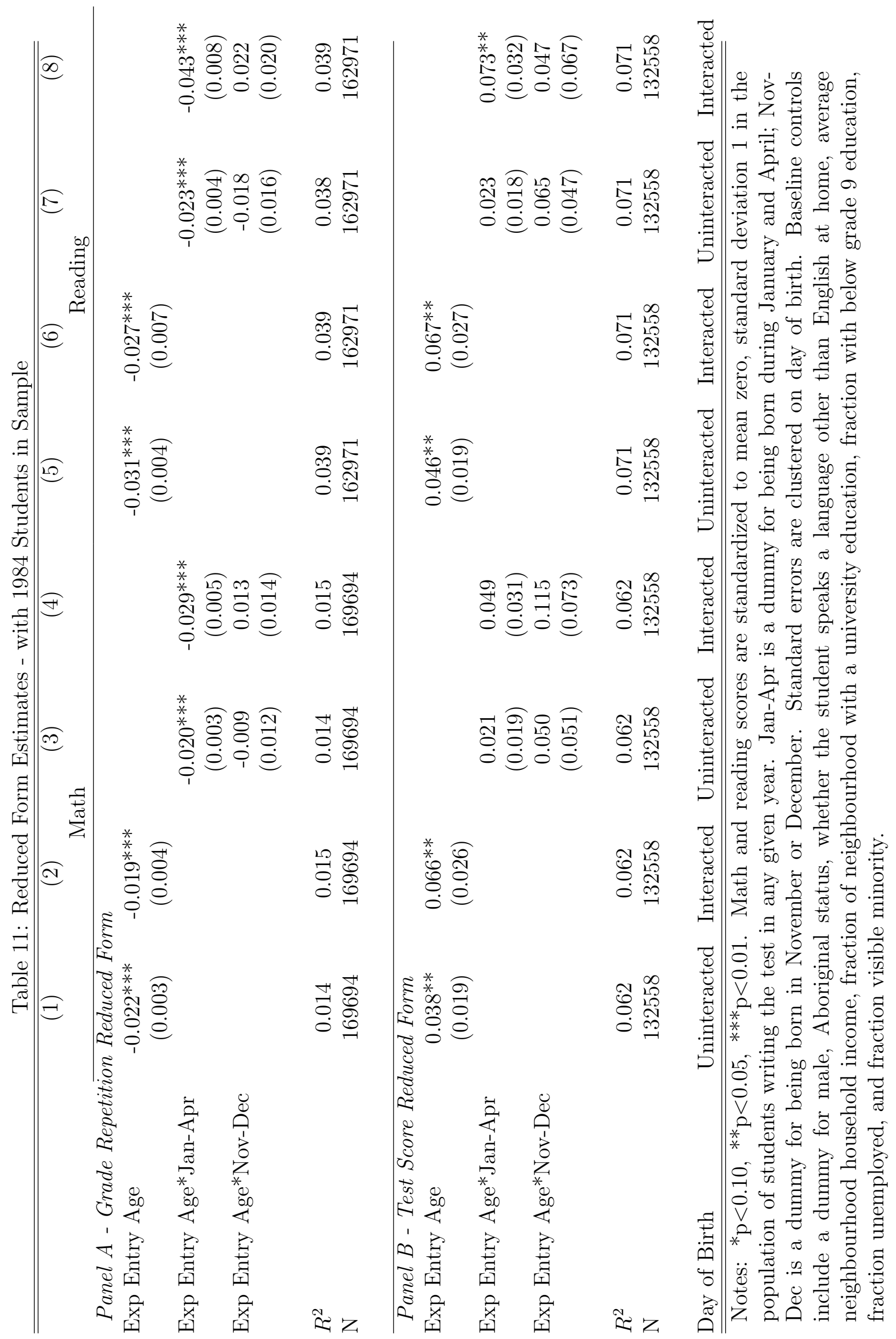




\section{School Entry Age}

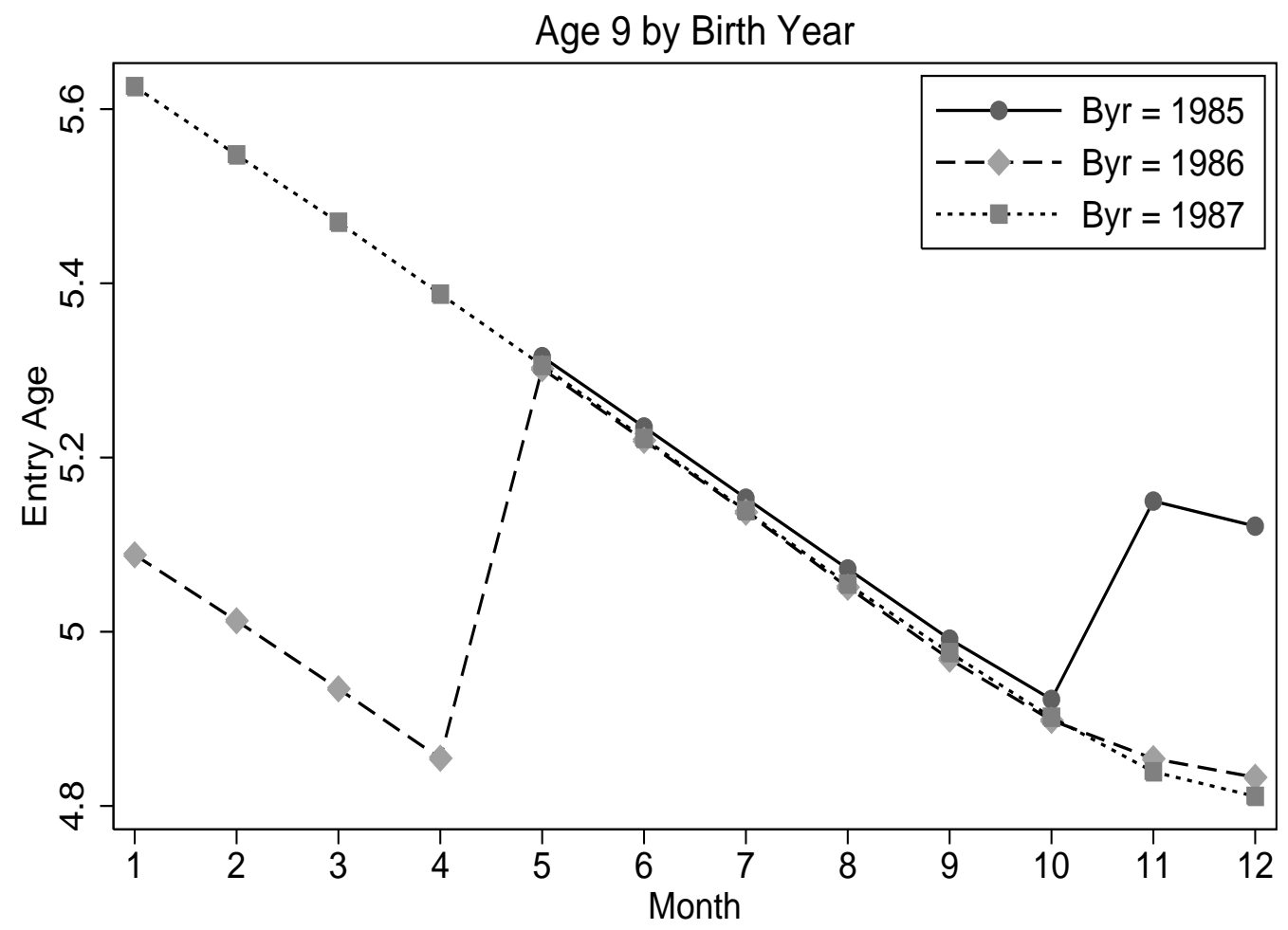

Figure 1: Predicted Entry Student Entry Ages in BC, Students Born 1985-1987 

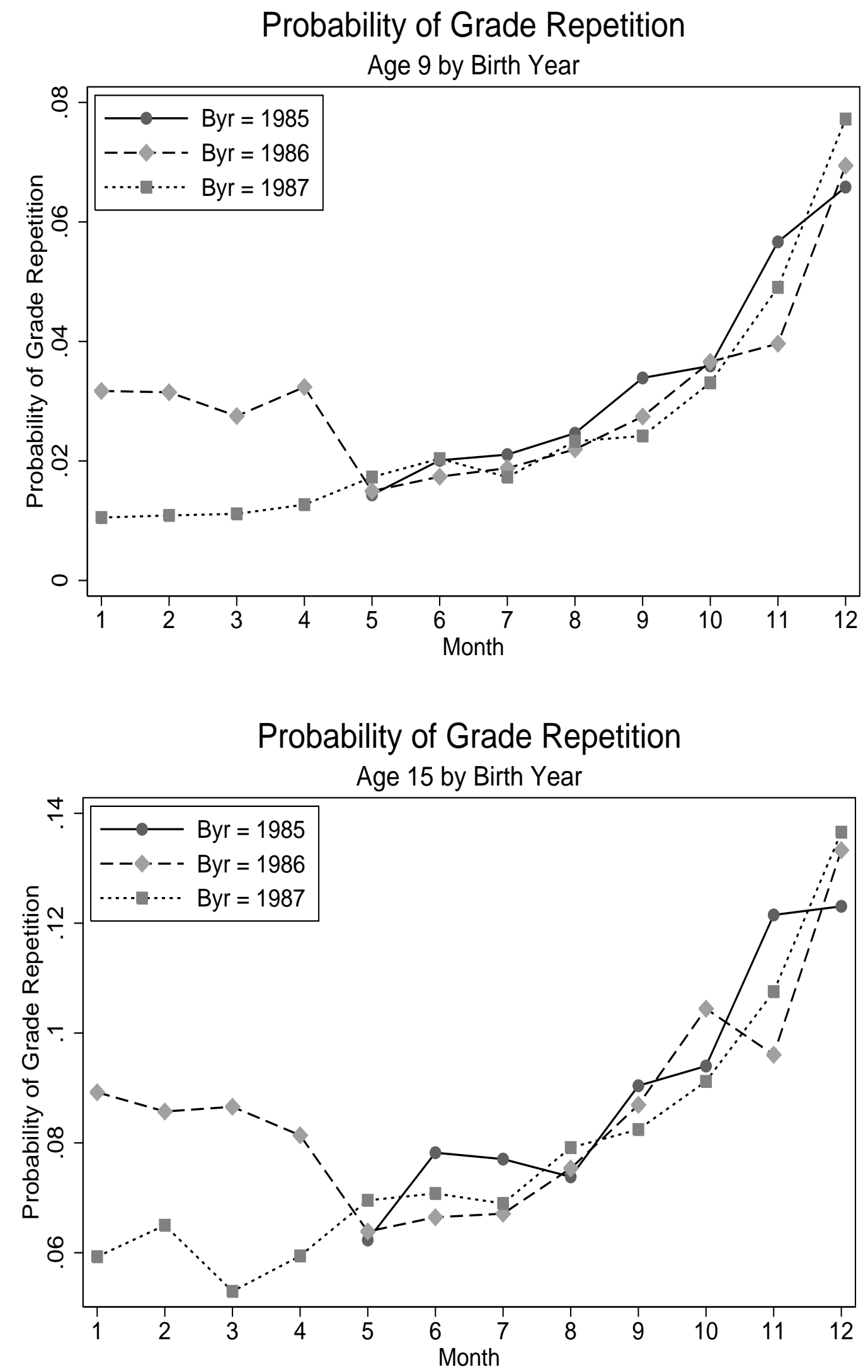

Figure 2: Probability of Grade Repetition in BC, Students Born 1985-1987 

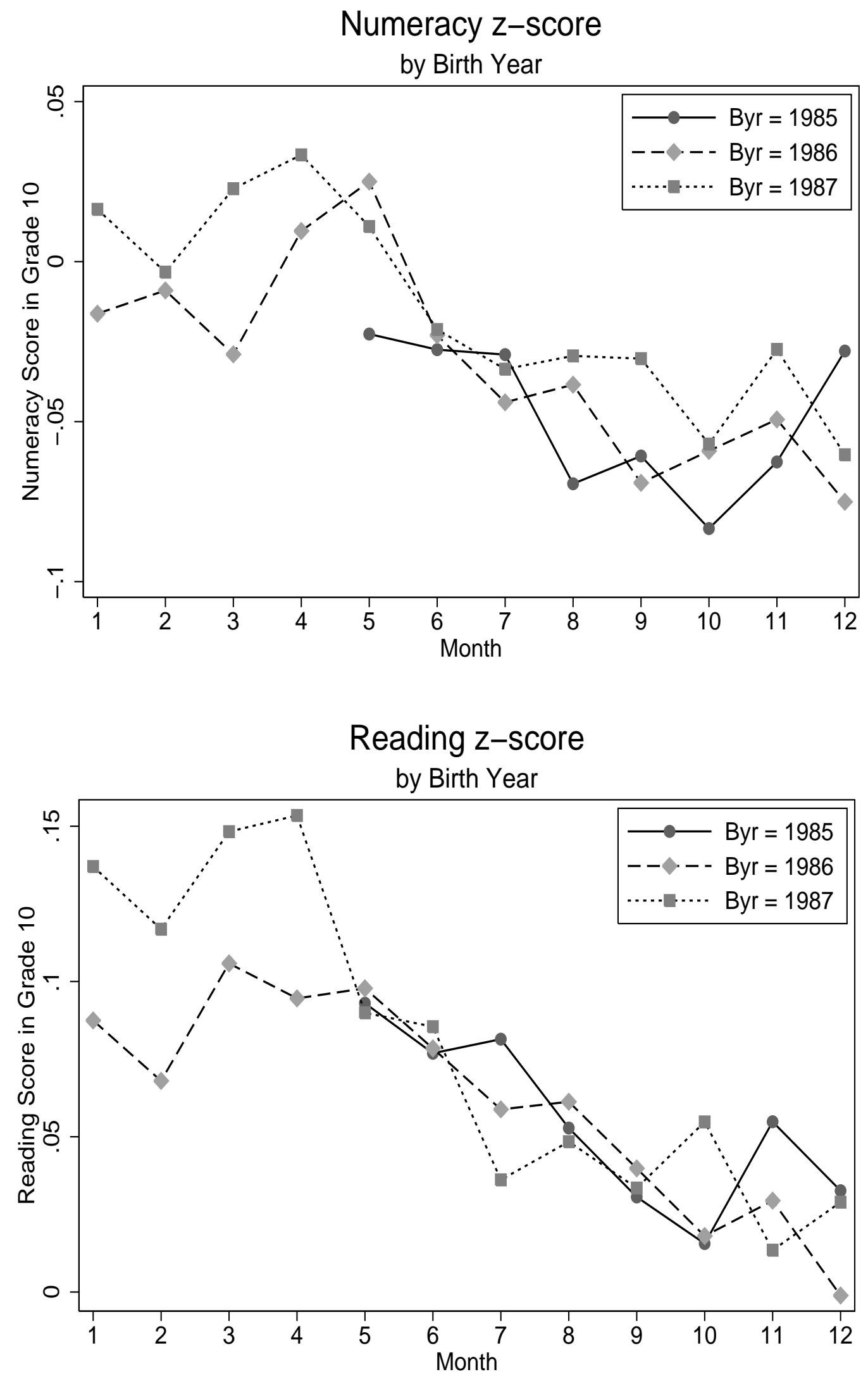

Figure 3: Grade 10 Math and Reading Test Scores, Students Born 1985-1987 
Attrition From Sample at age 9

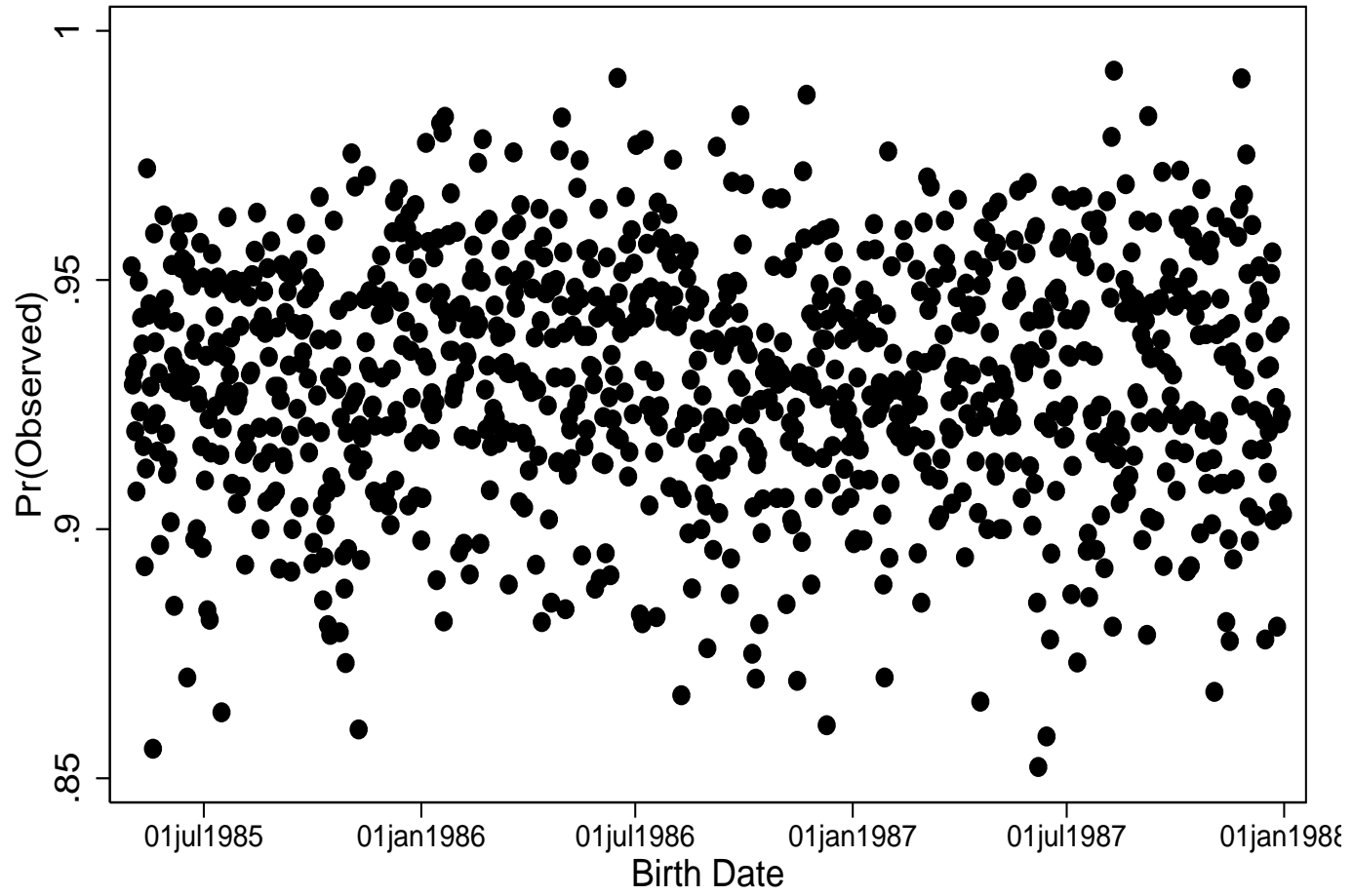

Attrition From Sample for Grade 10 Test

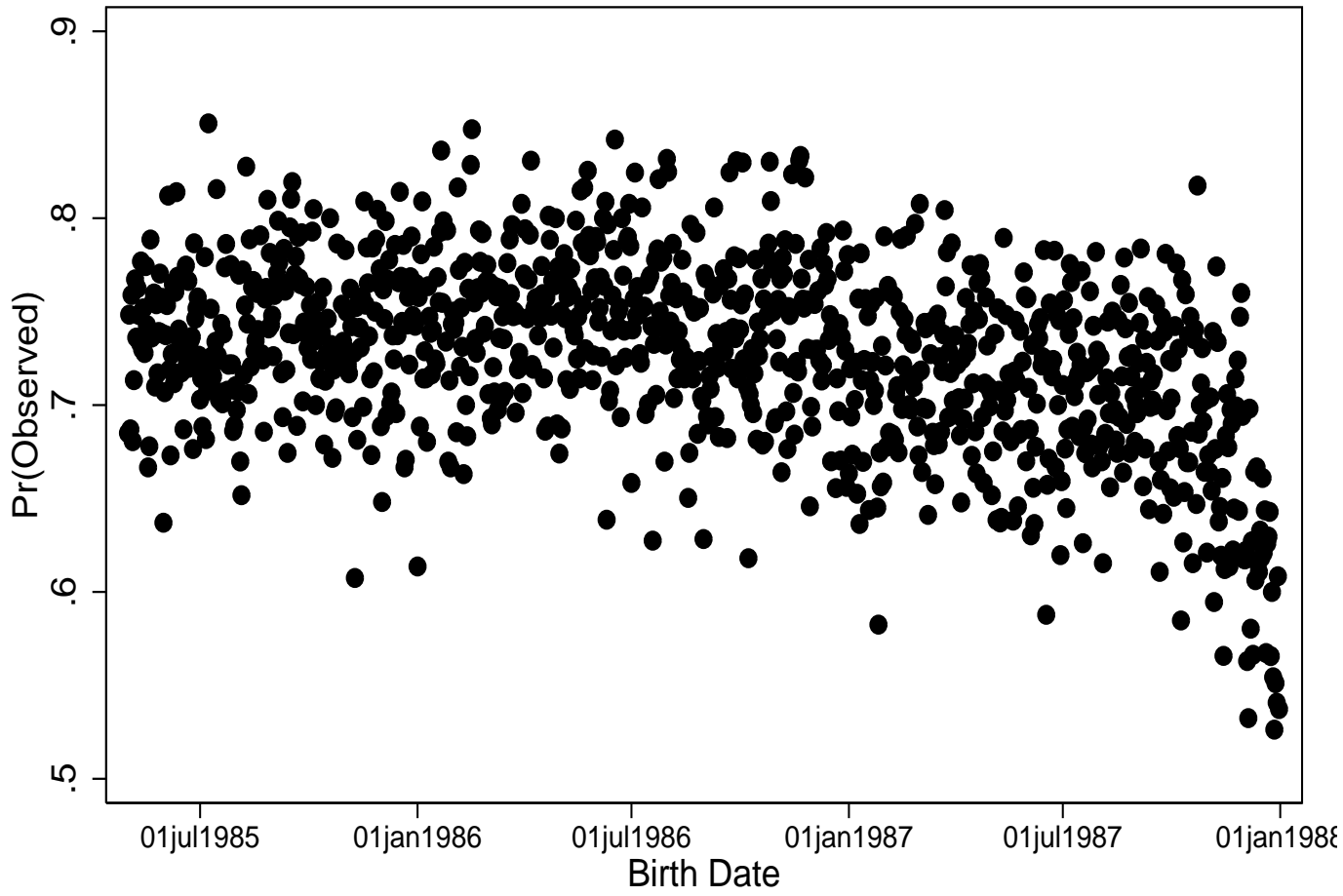

Figure 4: Likelihood of Remaining in Sample, Students Born 1985-1987 
Appendix 
Table A1: Full Set of Average Student Characteristics

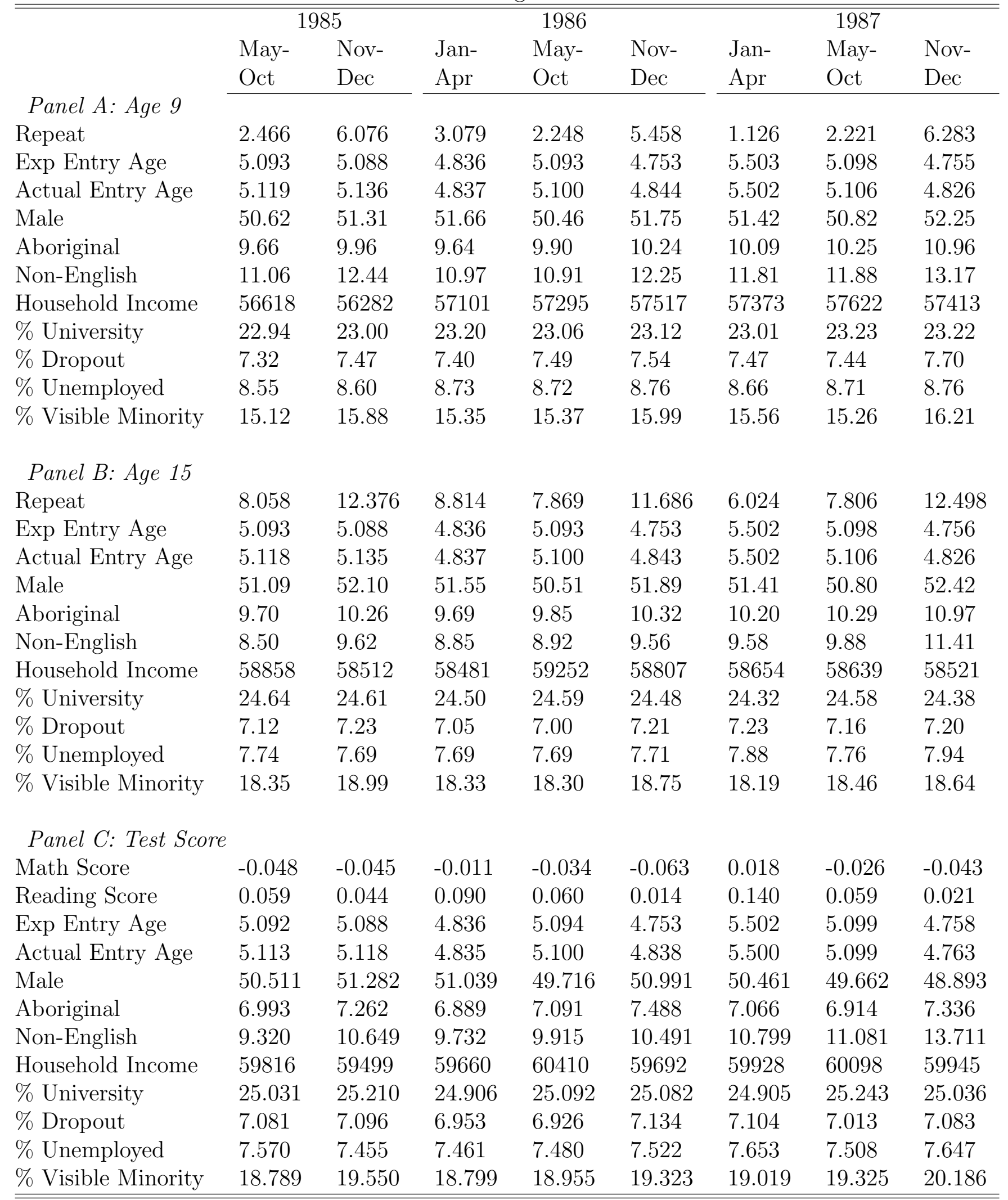

Notes: Repeat is the fraction repeating. Exp entry age is entry age according to the school entry rules, which may differ from actual entry age. Test scores are reported as $z$-scores, standardized across all students writing the math and reading test in a give year, respectively. 